\title{
2009/46
}

On the impact of trade on industrial structures:

The role of entry cost heterogeneity

Daisuke Oyama, Yasuhiro Sato,

Takatoshi Tabuchi and Jacques-François Thisse 
CORE

Voie du Roman Pays 34

B-1348 Louvain-la-Neuve, Belgium.

Tel (32 10) 474304

Fax (32 10) 474301

E-mail: corestat-library@uclouvain.be http://www.uclouvain.be/en-44508.html 


\title{
CORE DISCUSSION PAPER 2009/46
}

\section{On the impact of trade on industrial structures: The role of entry cost heterogeneity}

\author{
Daisuke OYAMA ${ }^{1}$, Yasuhiro SATO $^{2}$, \\ Takatoshi TABUCHI ${ }^{3}$ and Jacques-François THISSE ${ }^{4}$
}

August 2009

\begin{abstract}
This paper investigates the impacts of progressive trade openness, technological externalities, and heterogeneity of individuals on the formation of entrepreneurship in a two-country occupation choice model. We show that trade opening gives rise to a non-monotonic process of international specialization, in which the share of entrepreneurial firms in the large (small) country first increases (decreases) and then decreases (increases), with the global economy exhibiting first de-industrialization and then re-industrialization. When countries have the same size, we also show that strong technological externalities make the symmetric equilibrium unstable, generating equilibrium multiplicity, while sufficient heterogeneity of individuals leads to the stability and uniqueness of the symmetric equilibrium.
\end{abstract}

Keywords: entrepreneurship, trade liberalization, externality, heterogeneity, stability.

JEL Classification: F12, F16, J24, O14, R12

${ }^{1}$ Graduate School of Economics, Hitotsubashi University, Japan and PSE, France.

E-mail: oyama@econ.hit-u.ac.jp

${ }^{2}$ Graduate School of Economics, Osaka University, Japan. E-mail: ysato@econ.osaka-u.ac.jp

${ }^{3}$ Faculty of Economics, University of Tokyo, Japan. E-mail: ttabuchi@e.u-tokyo.ac.jp

${ }^{4}$ Université catholique de Louvain, CORE, B-1348 Louvain-la-Neuve, Belgium; Institute of Economic Research, Kyoto University, Japan; PSE, France, and CEPR. E-mail: Jacques.thisse@uclouvain.be. This author is also member of ECORE, the association between CORE and ECARES.

Earlier versions of this paper were circulated under the title "Trade and Entrepreneurship with Heterogeneous Workers". We wish to thank workshop participants at Academia Sinica, Hitotsubashi, Kobe University, Otaru University of Commerce, Taipei National University, and University of Tokyo for very useful comments and suggestions. D. Oyama, Y. Sato and T. Tabuchi acknowledge financial support by JSPS Grant-in-Aid for Young Scientists (B), Scientific Research (S), and Scientific Research (A). Part of this research was developed when D. Oyama visited CORE.

This paper presents research results of the Belgian Program on Interuniversity Poles of Attraction initiated by the Belgian State, Prime Minister's Office, Science Policy Programming. The scientific responsibility is assumed by the authors. 



\section{Introduction}

The aim of this paper is to study how progressive trade liberalization affects countries' industrial structure through both the channel of entrepreneurship and the process of creation/destruction of firms. By lowering trade costs, a deeper economic integration fosters more competition from abroad, which tends to lower prices and profits on the domestic market. This in turn reduces the incentives for individuals to start a new business. However, by facilitating exports lower trade costs make the foreign market bigger, which tend to compensate entrepreneurs for their lower markups. The outcome of this trade-off is, therefore, a priori undetermined. Moreover, besides market conditions, the decision of an individual to establish a firm also depends on her personal characteristics. Thus, we must account for the fact that economies are populated with individuals who are not born with the same abilities and/or do not face the same outside option. This in turn will lead us to view firms as having heterogeneous entry costs.

For a large number of observers, economic development should lead to the progressive disappearance of entrepreneurship (see, e.g., Lucas, 1978). Yet, one of the most striking and solid facts stressed by the economic and business literature devoted to entrepreneurship is the existence of a U-shaped relationship between the rate of new enterprises in the manufacturing and service sectors and the level of economic development among developed countries. More precisely, there has been a steadily decline in entrepreneurship from 1900 to 1970 with fewer and larger firms. Since then, a reversal of this pattern has emerged with the birth of many small businesses (see Wennekers et al., 2009 for a survey and empirical evidence). The period 1900-1960 has experienced several ups and downs in trade liberalization, so that one can hardly think of it as being one that went through a deep economic integration process (World Bank, 1991; World Trade Organization, 2001). By contrast, the period starting after 1960 has seen a growing number of de- 
veloped countries dismantling their trade barriers (e.g., the EU, NAFTA). It seems natural, therefore, to investigate the potential links between the rate of new enterprises and the degree of integration. Our results provide a rationale for this relationship that otherwise remains unexplained. ${ }^{1}$

In what follows, we develop a setting that combines (i) a two-country trade setting in which the manufacturing sector operates under monopolistic competition and increasing returns, and (ii) an occupational choice approach in which heterogeneous individuals are entitled to be either a worker in an existing firm or an entrepreneur producing a new variety. The monopolistic competition setting appears to be especially well suited to analyze the creation of small businesses that have a limited market power, while product differentiation allows us to capture the fundamental idea that entrepreneurs are often market-makers. Furthermore, assuming heterogeneous individuals means that they have both idiosyncratic ideas and subjective attitudes toward entrepreneurship (Casson, 2005); they also devote personal effort and resources to establishing a firm (Jovanovic, 1994). The heterogeneity across individuals is translated in our setting in firms facing heterogeneous entry costs.

Our main results all reveal that trade liberalization has contrasted effects on countries through the creation and destruction of local firms. First of all, we find that the large country always retains a more than proportional share of firms, meaning that the home market effect holds (Krugman, 1980). This does not mean, however, that this country always benefits from lower trade costs. Indeed, trade liberalization does not translate into a simple and monotonic process of international specialization. Specifically, we will

\footnotetext{
${ }^{1}$ Although the results are not directly comparable, our analysis also concurs with the empirical evidence provided by Eeckhout and Jovanovic (2008) when we restrict ourselves to two types of countries: since the 1970s, the high skilled economies have seen a disproportionate increase in the share of managerial occupations compared with the middle skilled economies.
} 
see that the whole process of economic integration is to be split into two contrasting phases. In the first one, which occurs when trade costs remain relatively high, the industrial basis of the large country grows whereas that of the small country shrinks. Because consumers living in the small country have access to a much wider range of varieties, the local firms lose a substantial market share in their home market, thus reducing the incentives for people to become entrepreneurs. On the contrary, the large country firms benefit from a market expansion effect that leads more people to become entrepreneurs. Consequently, during the first phase of the integration process, countries become more dissimilar and inequality rises.

In the second phase, which is reached when trade costs are low enough, we observe a complete reversal in the foregoing tendencies. On the one hand, trade costs are now sufficiently low for the small country firms to benefit from a much larger market, thus inducing more individuals to become entrepreneurs. On the other hand, because foreign competition is exacerbated by lower trade costs, business is less profitable in the large country. Hence, during the second phase, economic integration fosters convergence between countries. Combining the foregoing results will then allow us to show, under a mild regularity condition, that the number of firms in the global economy decreases during our first phase, but grows during the second one. To the extent that the degree of development is highly correlated to the level of integration in developed economies, this nonmonotonic process provides a rationale for the U-shaped curve mentioned earlier. In addition, it is well documented that the rate of new firm formation significantly varies across countries (Audretsch and Feldman, 2004). We illustrate this fact by showing how the creation and destruction of firms vary in countries having different sizes. $^{2}$

\footnotetext{
${ }^{2}$ Eeckhout and Jovanovic (2008) develop a model of occupational choice in which skills are distributed over a continuum of countries. They show that global labor market integration, which allows firms to employ foreign workers through outsourcing, leads to a
} 
This is not the end of the story, however. The empirical literature highlights another major fact, namely entrepreneurship cannot be explained solely by individual characteristics of people, as assumed in the occupational choice model (Jovanovic, 1982; Holmes and Schmitz, 1990). It must also account for the social and institutional environment in which they operate (Shane and Venkataraman, 2000). Specifically, business analysts argue that individuals are influenced by what others do, especially when facing fuzzy market conditions. Such influences, which are reminiscent of bandwagon effects, may be subsumed in a network externality (Minniti, 2005). In the same vein, we know from economic geography that the clustering of a growing number of firms gives rise to agglomeration economies, which lower the production costs of firms located in the cluster and, therefore, facilitate the creation of new firms, especially small entrants (Glaeser and Kerr, 2008). Such economies stem from a wider array of intermediate suppliers and a larger labor pool available to firms, as well as from information spillovers that develop within the cluster (Duranton and Puga, 2004). Both agglomeration and network economies generate external increasing returns with respect to the cluster size and may, therefore, be captured in the same way. More precisely, these two strands of literature are reconciled in our framework by assuming that potential entrepreneurs are positively affected by an externality whose intensity rises with the number of local entrepreneurs. Though somewhat ad hoc, such a modeling strategy is consistent with various underlying microeconomic mechanisms. It is worth stressing that it entails no loss of generality as long as we confine ourselves to a positive disproportionately high share of entrepreneurs in high-skilled countries. We obtain a similar result during the first phase of integration, whereas the small economy catches up during the second phase. Note also that Eeckhout and Jovanovic show that the distribution of gains from trade is U-shaped across countries, whereas in our setting, the global number of varieties is U-shaped with respect to the degree of integration in the product market. 
analysis.

In order to uncover the pure impact of agglomeration externalities on the nature of trade while keeping the analysis tractable, we consider the special case in which countries are identical. In such a case, there always exists a symmetric equilibrium where their industrial structures are identical; when the externality is weak, it is unique and globally stable. However, when the externality is sufficiently strong, the symmetric pattern ceases to be a stable equilibrium. Instead there are multiple asymmetric equilibria that are now stable, a feature that does not depend on the assumption of symmetric countries. To put it differently, once it is recognized that the entrepreneurship process is subject to a sufficient amount of agglomeration/network externalities, it appears that trade liberalization favors the emergence of inequalities between countries that are otherwise identical. Such a result points to the exacerbation of the tendencies toward inequality but the multiplicity of stable equilibria makes it hard to predict which country will benefit from the externalities.

Our second aim is to emphasize the fact that the heterogeneity of individuals acts as a force which tends to smooth out the destabilizing effects of the agglomeration externality. By increasing the degree of heterogeneity within the population according to specifications that will be explained below, we are able to establish the following two results. First, we show that a sufficient amount of "local" heterogeneity in the vicinity of the symmetric equilibrium overcomes the impact of the agglomeration externality and restores the local stability of this equilibrium. Second, allowing for a large amount of "global" heterogeneity suffices to guarantee the uniqueness, hence the global stability, of the symmetric equilibrium. Because there is ample evidence that individuals have very contrasted attitudes toward entrepreneurship, these two results suggest that the emphasis put on the network externality in the business literature may not be warranted. They 
also shed light on the macroscopic consequences of microeconomic attitudes: more heterogeneity at the individual level would be accompanied by less disparity at the global level. Conversely, more homogeneous individuals could strengthen the impact of the network externality, thereby exacerbating international inequalities. Thus, as shown by Herrendorf et al. (2000) in a different context, heterogeneity has a stabilizing effect. Finally, we compare these two results to those derived in other models where the idea of heterogeneity has been applied. As will be seen, the similarity between results obtained in settings that otherwise vastly differ suggests that there is probably a general principle at work.

Note that another aspect of firm heterogeneity has been recently explored by Melitz (2003), Helpman et al. (2004) and Melitz and Ottaviano (2008) among others. They aim to explain the well-documented fact that the most productive firms export while less efficient firms focus on their local markets only, the least efficient ones exiting the market. Once it is recognized that firms differ in marginal production costs, these authors show that market integration exacerbates this discrepancy in export strategies because lower trade costs intensify product market competition and trigger a selection effect of firms located in each country. In our paper, firms know their types before entry and are heterogeneous in their average production costs, whereas Melitz and others assume that firms know their types after entry and observe that they are heterogeneous in their marginal production costs. What drives firm heterogeneity is ultimately an empirical question. Whatever the answer, when firms are ex ante heterogeneous in marginal costs instead of entry costs, the main results of our analysis remain valid. The main difference between the two approaches is that inefficient firms do not enter the market in ours because they know ex ante their types. In Melitz (2003), firms are ex ante homogeneous and observe during the interim that they have different marginal costs. The inefficient firms then exit the 
market whereas in our model they refrain from entering. Note that, in the two approaches, the ex post productivity distributions are observationally equivalent.

Our paper also bears some resemblance with new economic geography (Fujita and Thisse, 2009). Krugman (1980) deals with the mobility of homogeneous firms in a setting which involves asymmetric countries, monopolistic competition and increasing returns. He shows that the large country accommodates a more than proportional share of firms, while lowering trade costs exacerbates the agglomeration of firms in the large country. However, our paper differs from Krugman (1980) in two fundamental aspects. First, the endogenous number of firms is determined through the creation and destruction of firms involving heterogeneous entry costs. Second, there is no magnification of the home market effect where, as integration proceeds, the relative share of the manufacturing sector in the large country keeps rising. ${ }^{3}$ Amiti and Pissarides (2005) allow for heterogeneous workers and study the relationship between skill mismatch and firm agglomeration. They show that decreasing trade costs induce the monotonic agglomeration of firms. We also differ from Nocke (2006) where individuals decide whether or not to become entrepreneurs in the country in which they choose to live. As a conclusion, we find it fair to say that new economic geography has gone into full circle in that our paper captures several features of this field without assuming factor mobility between countries.

The remaining of the paper is organized as follows. The model and some preliminary results are presented in Section 2. Section 3 studies the impact of trade liberalization on countries' industrial structure. The role of network

\footnotetext{
${ }^{3}$ The U-shaped relationship between industrialization and trade costs we uncover also bears some resemblance with the main outcome obtained by Krugman and Venables (1995), but it arises for very different reasons since firms are geographically immobile in our setting. It is worth stressing, however, that Krugman and Venables (1995) use simulations only.
} 
externalities and the stabilizing effect of individuals' heterogeneity are dealt with in Section 4. Section 5 concludes.

\section{The model and intermediate results}

\subsection{The economy}

The economy involves two goods and two countries $i=1,2$ with a population of size $m_{1}$ and $m_{2}$, respectively; without loss of generality, we assume that $m_{1} \geq m_{2}$. Individuals are entitled to be either a worker in an existing firm or an entrepreneur launching a firm that produces a new variety. Our focus being on the heterogeneity of firms in terms of entry costs, we choose to model this idea by assuming that potential entrepreneurs have different opportunity costs, thus implying that they incur different costs when they choose to enter the market as an entrepreneur. Formally, we assume that an individual of type $\alpha$ is endowed with $\alpha$ efficiency units of labor and 1 unit of entrepreneurship. Types of individuals living in country $i$ are distributed according to the distribution function $F_{i}:\left[\underline{\alpha}_{i}, \bar{\alpha}_{i}\right] \rightarrow\left[0, m_{i}\right]$ with $0 \leq \underline{\alpha}_{i}<\bar{\alpha}_{i}$, which has a differentiable density function $f_{i}$ such that $f_{i}(\alpha)>0$ for all $\alpha \in\left[\underline{\alpha}_{i}, \bar{\alpha}_{i}\right]$.

Individuals are internationally immobile and have the same quasi-linear log-utility with respect to a continuum $N$ of varieties of a (horizontally) differentiated good $(M)$ and a homogeneous good $(A)$ :

$$
U=\mu \ln M+A \quad \mu>0
$$

where the subutility over the varieties is of the CES-type:

$$
M=\left[\int_{0}^{N} q(x)^{\frac{\sigma-1}{\sigma}} \mathrm{d} x\right]^{\frac{\sigma}{\sigma-1}}
$$

with $\sigma>1$ being the elasticity of substitution between any two varieties. ${ }^{4}$

\footnotetext{
${ }^{4}$ Such preferences are also used by Martin and Rogers (1995) and Pflüger (2004) in trade and geography models.
} 
Although quasi-linear preferences rank far behind homothetic preferences in general equilibrium models of trade, Dinopoulos et al. (2007) show that "quasi-linear preferences behave reasonably well in general-equilibrium settings" . Note, however, that our results remain valid when the upper-tier utility is of the Cobb-Douglas type. ${ }^{5}$ We have chosen to work with a quasilinear specification because it allows for a simple and neat presentation of our results. All individuals are endowed with $\bar{A}>0$ units of the homogeneous good. The initial endowment $\bar{A}$ is supposed to be larger than $\mu$ for the consumption of this good to be strictly positive at the market outcome. Consequently, our setting involves no income effect.

The differentiated good $M$ is produced by the manufacturing sector under increasing returns and monopolistic competition, using both entrepreneurs and workers. More precisely, producing $q$ units of a variety requires 1 unit of entrepreneurship and $c q$ units of labor (without loss of generality, we set $c=1$ by choosing the unit of good $M$ ). Hence, firms are heterogeneous in terms of entry cost. Indeed, an individual of type $\alpha$ incurs an opportunity cost equal to $\alpha$ when she chooses to operate in the manufacturing sector, so that different firms have different entry costs. ${ }^{6}$ In addition, the total mass $N=n_{1}+n_{2}$ of firms is endogenous since the mass of country- $i$ entrepreneurs $n_{i}$ is endogenous. Finally, shipping one unit of a differentiated good requires $\tau \geq 1$ units of this good (the iceberg trade cost); in particular, zero trade cost means $\tau=1$, whereas countries are autarkic when $\tau \rightarrow \infty$.

The homogeneous good $A$ is supplied under perfect competition using labor as the only input of a constant-returns technology. The unit input requirement is set to one by choice of units.

Recall that our primary purpose is to investigate how progressive de-

\footnotetext{
${ }^{5}$ Proofs are available from the authors upon request.

${ }^{6}$ In an alternative interpretation, the entry decision is associated with a personal effort made by individuals. In this context, individuals are heterogenous in the effort cost $\alpha$ borne to become entrepreneurs.
} 
crease in trade costs for the industrial good affects the sectoral structure of each country. In order to isolate this effect, we choose to work with a setting in which workers' wage is equalized between the two countries. This is guaranteed by the assumption of zero trade cost for the homogeneous good, which also enables us to capture the intuitive idea that the homogeneous good is standardized and easy to ship in bulk, whereas the industrial good is more sophisticated and, therefore, costly to trade. ${ }^{7}$ This makes the homogeneous good the natural choice for the numéraire. Consequently, in equilibrium, market wages are the same in both countries and equal to 1 . This in turn implies that an $\alpha$-type worker has an income equal to $\alpha$. In an entrepreneurship equilibrium to be defined below, an individual of type $\alpha$ in country $i$ becomes an entrepreneur if and only if she earns an salary $w_{i}$ higher than $\alpha$. This has two major implications. First, the entry process displays decreasing returns since the relative cost of firm creation goes up since more and more efficient workers are drawn away from production. Second, workers' average income rises when the mass of firms operating in the manufacturing sector increases. In other words, our model captures the fact that a rising number of entrepreneurs leads to a higher average income across workers (Lucas, 1978).

\subsection{The market equilibrium}

Fixing the number of entrepreneurs $n_{1}$ and $n_{2}$ in each country, we now determine the market equilibrium and the corresponding entrepreneurs' salaries as functions of $n_{1}$ and $n_{2}$. Let $p_{i j}$ denote the mill price charged by a firm located in country $i=1,2$ to its customers living in country $j=1,2$. The individual demands in countries $i$ and $j \neq i$ for variety $x \in[0, N]$ produced

\footnotetext{
${ }^{7}$ See, e.g., Krugman (1991) and Helpman et al. (2004) for a similar assumption.
} 
in country $i$ are respectively given by

$$
q_{i i}=\frac{\mu P_{i}^{\sigma-1}}{p_{i i}^{\sigma}} \quad q_{i j}=\frac{\mu P_{j}^{\sigma-1}}{\left(\tau p_{i j}\right)^{\sigma}}
$$

where $P_{i}$ is the price index of the differentiated good in country $i$. Since all firms located in country $i$ charge the same mill price in country $j$, the price index in country $i$ is given by

$$
P_{i}=\left[N_{i} p_{i i}^{-(\sigma-1)}+N_{j}\left(\tau p_{j i}\right)^{-(\sigma-1)}\right]^{\frac{-1}{\sigma-1}} .
$$

Note that (2.1) implies that a country- $i$ individual consumes $\mu / P_{i}$ units of the manufactured goods, thus implying that her expenditure on this good is equal to $\mu$. Therefore, country- $i$ 's expenditure on good $M$ is constant and equal to $\mu m_{i}$.

The profit of a country- $i$ firm is as follows:

$$
\pi_{i}=\left(p_{i i}-1\right) q_{i i} m_{i}+\left(p_{i j}-1\right) \tau q_{i j} m_{j}-w_{i}
$$

thus implying that its equilibrium mill prices are given by

$$
p_{i i}^{*}=p_{i j}^{*}=\frac{\sigma}{\sigma-1} .
$$

Let $\phi:=\tau^{1-\sigma} \in[0,1]$ be the degree of trade openness: a larger value of $\phi$ means lower trade costs, with $\phi=0$ when $\tau \rightarrow \infty$ and $\phi=1$ when $\tau=1$. Then, the equilibrium price index is expressed as

$$
P_{i}=\frac{\sigma}{\sigma-1}\left(n_{i}+\phi n_{j}\right)^{-\frac{1}{\sigma-1}} .
$$

Under free entry and exit, whence zero profits, the equilibrium entrepreneur income in country $i$ is given by a firm's operating profits:

$$
w_{i}\left(n_{i}, n_{j}\right)=\frac{1}{\sigma}\left(\frac{\mu m_{i}}{n_{i}+\phi n_{j}}+\phi \frac{\mu m_{j}}{n_{j}+\phi n_{i}}\right) .
$$

Thus, the equilibrium income prevailing in country $i$ decreases with the number of entrepreneurs in this country. It also decreases with the number 
of entrepreneurs in country $j$ because trade makes the two national labor markets interdependent through the mass of varieties they trade. Last, since operating profits are higher, a stronger preference for the industrial good (i.e., larger $\mu$ ) and/or more differentiated varieties (i.e., lower $\sigma$ ) leads to higher equilibrium salaries. Note that, in equilibrium, an entrepreneur's salary $w_{i}$ exceeds her opportunity cost $\alpha$.

The expression (2.3) may be given a very intuitive interpretation. The first bracketed term is the revenue gleaned by a country- $i$ firm in its domestic market, whereas the second stands for the revenue gleaned in the foreign market, which is "discounted" by $\phi \in[0,1]$ on account of the resources needed to sell abroad. All firms compete for the total expenditure on the manufactured good spent by country-i's residents, which is equal to $\mu m_{i}$. This "pie" is equally divided among country- $i$ firms, but not between country- $i$ firms and country- $j$ firms because of the existence of trade costs $(0<\phi<1)$. Furthermore, the pie accruing to a country- $i$ firm is distributed between the entrepreneur and the workers according to the shares $\left(p^{*}-1\right) / p^{*}$ and $1 / p^{*}$, respectively, where $p^{*}=\sigma /(\sigma-1)$ is the equilibrium mill price. This implies that an entrepreneur receives a fraction $1 / \sigma$ of the pie. Then, for any given $n_{1}$ and $n_{2}$, the following equality must hold at the market equilibrium:

$$
\sum_{i=1,2} w_{i}\left(n_{1}, n_{2}\right) n_{i}=\frac{\mu}{\sigma}\left(m_{1}+m_{2}\right)
$$

\subsection{The entrepreneurship equilibrium}

We now describe the equilibrium occupational choices. An $\alpha$-type individual living in country $i$ earns $\alpha$ as a worker and chooses to become an entrepreneur if and only if her worker income is less than the earnings she makes as an entrepreneur:

$$
\alpha \leq w_{i}\left(n_{i}, n_{j}\right)
$$


so that the mass of entrepreneurs in this country is given by $F_{i}\left[w_{i}\left(n_{i}, n_{j}\right)\right] .{ }^{8}$ A pair $\left(n_{1}^{*}, n_{2}^{*}\right)$ is an entrepreneurship equilibrium if and only if

$$
n_{1}^{*}=F_{1}\left[w_{1}\left(n_{1}^{*}, n_{2}^{*}\right)\right] \quad n_{2}^{*}=F_{2}\left[w_{2}\left(n_{1}^{*}, n_{2}^{*}\right)\right] .
$$

Observe that $\partial F_{i}\left[w_{i}\left(n_{i}, n_{j}\right)\right] / \partial n_{j}<0$, so that entrepreneurship decisions are strategic substitutes between countries. This property relies on the fact that firms compete across countries and does not depend on the specific features of our model.

Since $w_{i}\left(n_{1}^{*}, n_{2}^{*}\right)=F_{i}^{-1}\left(n_{i}^{*}\right)$ holds whenever $\left(n_{1}^{*}, n_{2}^{*}\right)$ is an entrepreneurship equilibrium for some $\phi$, by equation (2.4) the equilibrium must always lie on the locus of

$$
E\left(n_{1}, n_{2}\right):=F_{1}^{-1}\left(n_{1}\right) n_{1}+F_{2}^{-1}\left(n_{2}\right) n_{2}-\frac{\mu}{\sigma}\left(m_{1}+m_{2}\right)=0
$$

regardless of the value of $\phi$. Observe that this locus is downward sloping in the $n_{1}-n_{2}$ plane because of strategic substitutability of entrepreneurship decisions between countries.

Observation 2.1. The locus of $E\left(n_{1}, n_{2}\right)=0$ is downward sloping.

In other words, if the equilibrium number of entrepreneurs in country $i$, $n_{i}^{*}$, increases, then $n_{j}^{*}$ must decrease in $j$.

It remains to find conditions for an entrepreneurship equilibrium to exist. First, note that (2.3) implies that $w_{i}$ has a minimizer $w_{i}^{\min }>0$ independent of $\sigma$. The continuous function $w_{i}$ also has a maximizer $w_{i}^{\max }$ in the compact set $\left[F\left(w_{1}^{\min }\right), m_{1}\right] \times\left[F\left(w_{2}^{\min }\right), m_{2}\right]$. Assume that the interval $\left(\underline{\alpha}_{i}, \bar{\alpha}_{i}\right)$ is wide enough to include $\left[w_{i}^{\min }, w_{i}^{\max }\right]$, which implies that there are always some individuals with sufficiently low $\alpha$ who choose to become entrepreneurs and some with sufficiently high $\alpha$ who choose to become workers, whatever the others' choice. Under these conditions, we may restrict the

\footnotetext{
${ }^{8}$ An individual being negligible, her occupational choice has no impact on the mass of available varieties. Thus, maximizing income amounts here to maximizing utility.
} 
domain of $F_{i} \circ w_{i}$ over the compact and convex set $\left[F_{1}\left(w_{1}^{\min }\right), F_{1}\left(w_{1}^{\max }\right)\right] \times$ $\left[F_{2}\left(w_{2}^{\min }\right), F_{2}\left(w_{2}^{\max }\right)\right]$. Furthermore, the continuous function $F_{i} \circ w_{i}$ takes its value in $\left[F_{i}\left(w_{i}^{\min }\right), F_{i}\left(w_{i}^{\max }\right)\right]$ because $F_{i}$ is increasing. Hence, Brouwer's fixed point theorem implies that the mapping $\left(F_{1} \circ w_{1}, F_{2} \circ w_{2}\right)$ has a fixed point in the restricted domain of $\left(n_{1}, n_{2}\right)$, and this point is an entrepreneurship equilibrium. We will assume throughout the rest of the paper that $\left[w_{i}^{\min }, w_{i}^{\max }\right] \subset\left(\underline{\alpha}_{i}, \bar{\alpha}_{i}\right)$ for $i=1,2$.

In the next section, we study how the shares of entrepreneurs-firms in both countries, whence the size and the international distribution of the manufacturing sector, react to gradual trade opening.

\section{The impact of trade opening}

In order to focus on the interactions between country size and trade openness, we consider the case in which the type distributions in the two countries are identical up to a scale parameter that reflects the country size, i.e., $\left[\underline{\alpha}_{i}, \bar{\alpha}_{i}\right]=[\underline{\alpha}, \bar{\alpha}]$, and $F_{i}(\alpha)=m_{i} G(\alpha)$ for a common distribution function $G:[\underline{\alpha}, \bar{\alpha}] \rightarrow[0,1]$. We assume that $G$ has a differentiable density $g$ and $g(\alpha)>0$ for all $\alpha \in[\underline{\alpha}, \bar{\alpha}]$. Accordingly, we focus on $s_{i}:=n_{i} / m_{i}$, the fraction of entrepreneurs in each country $i$. So, from now on, we refer to $\left(s_{1}^{*}(\phi), s_{2}^{*}(\phi)\right)$ as being the entrepreneurship equilibrium.

\subsection{National industrialization}

It follows directly from $(2.5)$ that $\left(s_{1}^{*}(\phi), s_{2}^{*}(\phi)\right)$ is an entrepreneurship equilibrium if and only if $s_{1}^{*}(\phi)$ and $s_{2}^{*}(\phi)$ satisfy the following two conditions:

$$
\begin{aligned}
& \bar{D}_{1}\left(s_{1}, s_{2} ; \phi\right):=G\left(\bar{w}_{1}\left(s_{1}, s_{2} ; \phi\right)\right)-s_{1}=0 \\
& \bar{D}_{2}\left(s_{1}, s_{2} ; \phi\right):=G\left(\bar{w}_{2}\left(s_{1}, s_{2} ; \phi\right)\right)-s_{2}=0
\end{aligned}
$$


where $\bar{w}_{i}:[0,1]^{2} \times[0,1] \rightarrow \mathbb{R}$ is the salary of an entrepreneur in country $i$, which is defined by

$$
\bar{w}_{i}\left(s_{1}, s_{2} ; \phi\right)=\frac{1}{\sigma}\left(\frac{\mu m_{i}}{m_{i} s_{i}+\phi m_{j} s_{j}}+\frac{\phi \mu m_{j}}{m_{j} s_{j}+\phi m_{i} s_{i}}\right) .
$$

It is readily verified that, for any $\left(s_{1}, s_{2}\right), \partial \bar{D}_{i} / \partial s_{j}<0$ for $i, j=1,2$. Furthermore, we have

$$
\left|\frac{\partial \bar{D}_{1}}{\partial s_{1}} / \frac{\partial \bar{D}_{1}}{\partial s_{2}}\right|>\left|\frac{\partial \bar{D}_{2}}{\partial s_{1}} / \frac{\partial \bar{D}_{2}}{\partial s_{2}}\right|
$$

To show it, observe that

$$
\left|\frac{\partial \bar{D}_{1}}{\partial s_{1}} / \frac{\partial \bar{D}_{1}}{\partial s_{2}}\right|>\left|\frac{\partial G\left(\bar{w}_{1}\right)}{\partial s_{1}} / \frac{\partial G\left(\bar{w}_{1}\right)}{\partial s_{2}}\right|=\left|\frac{\partial \bar{w}_{1}}{\partial s_{1}} / \frac{\partial \bar{w}_{1}}{\partial s_{2}}\right|
$$

while

$$
\left|\frac{\partial \bar{D}_{2}}{\partial s_{1}} / \frac{\partial \bar{D}_{2}}{\partial s_{2}}\right|<\left|\frac{\partial G\left(\bar{w}_{2}\right)}{\partial s_{1}} / \frac{\partial G\left(\bar{w}_{2}\right)}{\partial s_{2}}\right|=\left|\frac{\partial \bar{w}_{2}}{\partial s_{1}} / \frac{\partial \bar{w}_{2}}{\partial s_{2}}\right| .
$$

The desired result then follows from

$$
\left|\frac{\partial \bar{w}_{1}}{\partial s_{1}} \cdot \frac{\partial \bar{w}_{2}}{\partial s_{2}}\right| \geq\left|\frac{\partial \bar{w}_{1}}{\partial s_{2}} \cdot \frac{\partial \bar{w}_{2}}{\partial s_{1}}\right|
$$

which always holds.

Observation 3.1. In the $s_{1}-s_{2}$ plane,

1. the locus of $\bar{D}_{i}\left(s_{1}, s_{2}\right)=0$ is downward sloping;

2. $\bar{D}_{i}\left(t_{1}, t_{2}\right)>0$ if $\left(t_{1}, t_{2}\right)$ belongs to the south-west domain delineated by $\bar{D}_{i}\left(s_{1}, s_{2}\right)=0$, while $\bar{D}_{i}\left(t_{1}, t_{2}\right)<0$ if $\left(t_{1}, t_{2}\right)$ belongs to the north-east domain; and

3. at any entrepreneurship equilibrium $\left(s_{1}^{*}, s_{2}^{*}\right), \bar{D}_{1}\left(s_{1}, s_{2}\right)=0$ is steeper than $\bar{D}_{2}\left(s_{1}, s_{2}\right)=0$.

By continuity, the third statement implies that the equilibrium $\left(s_{1}^{*}(\phi), s_{2}^{*}(\phi)\right)$ is unique for any $\phi$. 
When each country is in autarky $(\phi=0)$ or when the two countries are fully integrated $(\phi=1)$, the entrepreneurs' salary is independent of the country size because

$$
\bar{w}_{i}(s, s ; 0)=\bar{w}_{i}(s, s ; 1)=\frac{\mu}{\sigma s}
$$

for any $s$ and $m_{1}, m_{2}$. Since

$$
\bar{D}_{i}(s, s ; 0)=\bar{D}_{i}(s, s ; 1)=G\left(\frac{\mu}{\sigma s}\right)-s
$$

holds regardless of the value of $m_{1}$ and $m_{2}$, it must be that $\bar{D}_{i}(\bar{s}, \bar{s} ; 0)=$ $\bar{D}_{i}(\bar{s}, \bar{s} ; 1)=0$, where $\bar{s} \in(0,1)$ is the unique solution to the equation

$$
G\left(\frac{\mu}{\sigma s}\right)-s=0 .
$$

Thus,

$$
s_{1}^{*}(0)=s_{2}^{*}(0)=s_{1}^{*}(1)=s_{2}^{*}(1)=\bar{s} .
$$

In other words, size does not matter for the share of entrepreneurs in the two polar cases in which trading is either prohibitively expensive or costless. Note, however, that all individuals are better off in the latter than in the former case because they have access to a wider array of varieties.

Let us now come to the more interesting case in which $0<\phi<1$. We then have:

Observation 3.2. (i) If $m_{1}=m_{2}$, then $s_{1}^{*}(\phi)=s_{2}^{*}(\phi)=\bar{s}$ for all $\phi \in(0,1)$.

(ii) If $m_{1}>m_{2}$, then $0<s_{2}^{*}(\phi)<s_{1}^{*}(\phi)<1$ for all $\phi \in(0,1)$.

Proof. (i) If $m_{1}=m_{2}$, then (3.1) implies that $\bar{w}_{i}(s, s ; \phi)$ is independent of $m_{1}$ and $m_{2}$. Hence, we have $s_{1}^{*}(\phi)=s_{2}^{*}(\phi)=\bar{s}$ for all $\phi \in(0,1)$.

(ii) If $m_{1}>m_{2}$, then we have $\bar{D}_{1}(\bar{s}, \bar{s} ; \phi)>0$ and $\bar{D}_{2}(\bar{s}, \bar{s} ; \phi)<0$ for all $\phi \in(0,1)$. By Observation 3.1, this implies that $\left(s_{1}^{*}(\phi), s_{2}^{*}(\phi)\right)$ lies below the bisector, i.e., $s_{1}^{*}(\phi)>s_{2}^{*}(\phi)$ for all $\phi \in(0,1)$.

Since $y_{2}^{\min }>\underline{\alpha}$ by assumption, it must be that $\bar{D}_{2}\left(s_{1}, 0 ; \phi\right)>0$ for any $s_{1}$ and $\phi$. This implies that $\bar{D}_{2}\left(s_{1}, 0 ; \phi\right)=0$ never intersects the $s_{1}$-axis, which 
in turn implies that $\left(s_{1}^{*}(\phi), s_{2}^{*}(\phi)\right)$ never lies on the $s_{1}$-axis, i.e., $s_{2}^{*}(\phi)>0$ for all $\phi \in(0,1)$. Likewise, $y_{1}^{\max }<\bar{\alpha}$ implies $s_{1}^{*}(\phi)<1$ for all $\phi \in(0,1)$. $\|$

From (2.6), observe that the equilibrium $\left(s_{1}^{*}(\phi), s_{2}^{*}(\phi)\right)$ always lies on the locus of

$$
\bar{E}\left(s_{1}, s_{2}\right):=m_{1} G^{-1}\left(s_{1}\right) s_{1}+m_{2} G^{-1}\left(s_{2}\right) s_{2}-\frac{\mu}{\sigma}\left(m_{1}+m_{2}\right)=0 .
$$

As in Observation 2.1, this locus is downward sloping in the $s_{1}-s_{2}$ plane. This implies that, as $\phi$ increases from 0 to $1, s_{1}^{*}(\phi)$ and $s_{2}^{*}(\phi)$ always move in opposite directions. Specifically, the equilibrium $\left(s_{1}^{*}(\phi), s_{2}^{*}(\phi)\right)$ starts from $(\bar{s}, \bar{s})$, moves continuously along the locus $\bar{E}\left(s_{1}, s_{2}\right)$, and ends up at $(\bar{s}, \bar{s})$. We will show below that $\left(s_{1}^{*}(\phi), s_{2}^{*}(\phi)\right)$ changes its direction only once. Since $\left(s_{1}^{*}(\phi), s_{2}^{*}(\phi)\right)$ is given by the intersection point of $\bar{E}\left(s_{1}, s_{2}\right)=0$ and $\bar{D}_{1}\left(s_{1}, s_{2} ; \phi\right)=0$, it suffices to show that, as $\phi$ increases from 0 to 1 , $\bar{D}_{1}\left(s_{1}, s_{2} ; \phi\right)=0$ changes its direction only once.

Lemma 3.3. For any given $\left(s_{1}, s_{2}\right)$, the equation $\bar{D}_{1}\left(s_{1}, s_{2} ; \phi\right)=0$ has at most two solutions in terms of $\phi$.

Proof. Fix any point $\left(s_{1}, s_{2}\right)$. We claim that

$$
\frac{\partial \bar{D}_{1}}{\partial \phi}=g\left(\bar{w}_{1}\right) \frac{\partial \bar{w}_{1}}{\partial \phi}
$$

changes its sign at most once. Since $g(\cdot)>0$, it is sufficient to show that $\partial \bar{w}_{1} / \partial \phi=0$ has at most one solution, which can be established by direct computation. Hence, $\bar{D}_{1}\left(s_{1}, s_{2} ; \phi\right)$ changes its slope at most once, which in turn implies that $\bar{D}_{1}\left(s_{1}, s_{2} ; \phi\right)=0$ has at most two solutions in $\phi$. \|

This has the following implication.

Observation 3.4. As $\phi$ increases from 0 to $1,\left(s_{1}^{*}(\phi), s_{2}^{*}(\phi)\right)$ changes its direction only once.

Proof. Fix any point $\left(t_{1}, t_{2}\right)$ on the locus of $\bar{E}\left(s_{1}, s_{2}\right)=0$. By continuity of the equilibrium with respect to $\phi$, it is sufficient to show that $\left(t_{1}, t_{2}\right)$ 


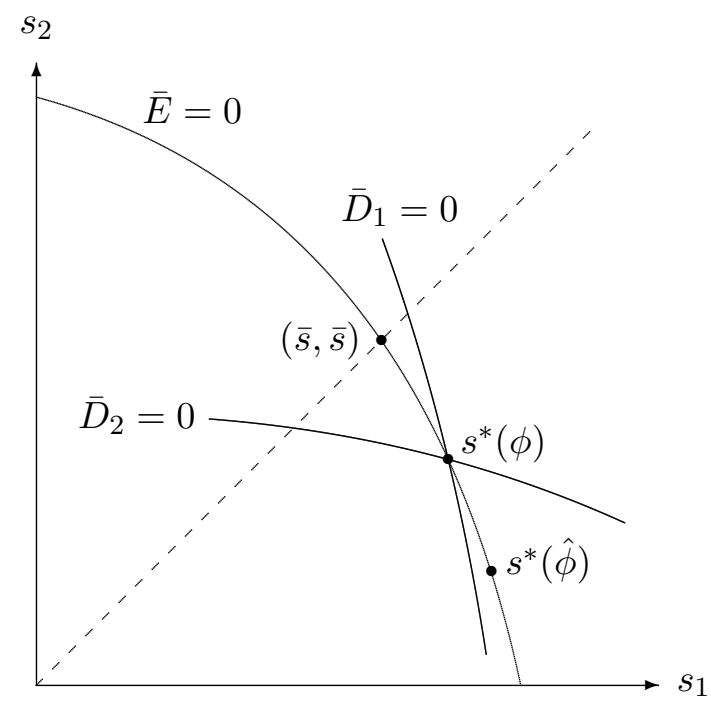

Figure 1: Entrepreneurship equilibrium

becomes an equilibrium for at most two distinct values of $\phi$. Furthermore, $\left(t_{1}, t_{2}\right)$ is an equilibrium only if it satisfies $\bar{D}_{1}\left(t_{1}, t_{2} ; \phi\right)=0$ for some $\phi$. Finally, Lemma 3.3 implies that there exist at most two such $\phi$ 's. $\|$

To sum up, we have:

Proposition 3.5. For all $\phi \in[0,1]$, there exists a unique entrepreneurship equilibrium $\left(s_{1}^{*}(\phi), s_{2}^{*}(\phi)\right)$.

(i) For any $m_{1}$ and $m_{2}, s_{1}^{*}(0)=s_{2}^{*}(0)=s_{1}^{*}(1)=s_{2}^{*}(1)=\bar{s}$.

(ii) If $m_{1}>m_{2}$, then $s_{1}^{*}(\phi)>s_{2}^{*}(\phi)>0$ for all $\phi \in(0,1)$. Furthermore, there exists a unique $\hat{\phi} \in(0,1)$ such that $\bar{s}<s_{1}^{*}(\phi)<s_{1}^{*}\left(\phi^{\prime}\right)$ and $\bar{s}>s_{2}^{*}(\phi)>$ $s_{2}^{*}\left(\phi^{\prime}\right)$ when $0<\phi<\phi^{\prime} \leq \hat{\phi}$, while $s_{1}^{*}(\phi)>s_{1}^{*}\left(\phi^{\prime}\right)>\bar{s}$ and $s_{2}^{*}(\phi)<s_{2}^{*}\left(\phi^{\prime}\right)<\bar{s}$ when $\hat{\phi} \leq \phi<\phi^{\prime}<1$.

(iii) If $m_{1}=m_{2}$, then $s_{1}^{*}(\phi)=s_{2}^{*}(\phi)=\bar{s}$ for all $\phi \in(0,1)$.

Figure 1 depicts the entrepreneurship equilibrium as well as the relevant loci. Since both countries exhibit a reversal in the evolution of their industrial structure at $\hat{\phi}$, we refer to the interval $(0, \hat{\phi})$ as describing the first phase of the integration process, while $(\hat{\phi}, 1)$ corresponds to the second one. 
Proposition 3.5 has several important implications. First, the share of entrepreneurs is always larger in the large country than in the small country. This implies that the large country is relatively more specialized in the manufacturing sector than the small country. This in turn means that the salary of an entrepreneur is higher in the large country than in the small one. Therefore, because $P_{1}^{*}<P_{2}^{*}$, both entrepreneurs and workers in country 1 are better off than their counterpart in country 2. Accordingly, we may safely conclude that, once countries have different sizes, spatial frictions in trade generate asymmetries in the international distribution of income and welfare.

Second, the global economy displays a home market effect. Recall that such an effect arises when the large country accommodates a more than proportional share of firms (Krugman, 1980). The share of country 1's industrial firms in the global economy is such that

$$
\frac{n_{1}^{*}(\phi)}{n_{1}^{*}(\phi)+n_{2}^{*}(\phi)}=\frac{m_{1} s_{1}^{*}(\phi)}{m_{1} s_{1}^{*}(\phi)+m_{2} s_{2}^{*}(\phi)}>\frac{m_{1}}{m_{1}+m_{2}}
$$

because $s_{1}^{*}(\phi)>s_{2}^{*}(\phi)$ once $0<\phi<1$ and $m_{1}>m_{2}$. In other words, the share of firms in the large country always exceeds its relative size.

Last, trade liberalization has a dramatic impact on each country's degree of industrialization. Indeed, trade links the two countries in a way such that one country always develops its industry at the expense of the other. More precisely, during the first phase of integration the number of entrepreneurs increases in the large country but decreases in the small one. This means that the large country gets more industrialized, whereas the small one experiences de-industrialization. During the first phase, the per capita income increases in the large country and decreases in the small one because both $s_{1}^{*}$ and $w_{1}^{*}$ rise, whereas $s_{2}^{*}$ and $w_{2}^{*}$ fall. The first phase thus agrees with the prediction made in new economic geography models in which, as trade costs go down, the share of firms grows in the large country, but decreases in the small one. However, there is no magnification effect as integration 
proceeds since the relative share of manufacturing in the large country no longer increases with further trade liberalization. Quite the opposite, during the second phase, the small country gradually recoups its industrial basis and the two industrial structures converge. At first glance, the creation of new firms through the development of entrepreneurship might be viewed as a substitute to the international mobility of capital and firms in the global economy. Results are different, however. There are two reasons for that. First, individuals choose to become entrepreneurs, instead of being endowed with units of capital. Second, entrepreneurs invest in their own country, while capital-owners seek the country with the highest rental rate of capital. Thus, individuals face different incentive structures in the two settings.

The above pattern may be explained as follows. As discussed in the introduction, trade liberalization gives rise to two conflicting effects that shape the global economy. The former, called the market expansion effect, finds its origin in the fact that exporting becomes easier, thus strengthening the incentives to become an entrepreneur. The latter, which we refer to as the market crowding effect, is the mirror image of the former: as it becomes easier for each country to import new varieties, the incentives to become an entrepreneur are weaker. Because of strategic substitutability of entrepreneurship decisions between countries, if one effect dominates the other in one country, the reverse must hold in the other one. In order to study the behavior of these two effects as $\phi$ varies from 0 to 1 , we take the partial derivative of (3.1) with respect to $\phi$ :

$$
\begin{aligned}
\frac{\partial \bar{w}_{i}}{\partial \phi}\left(s_{1}, s_{2} ; \phi\right)=\frac{1}{\sigma} & {\left[-\frac{\mu m_{i}}{m_{i} s_{i}+\phi m_{j} s_{j}} \cdot \frac{m_{j} s_{j}}{m_{i} s_{i}+\phi m_{j} s_{j}}\right.} \\
& \left.+\frac{\mu m_{j}}{m_{j} s_{j}+\phi m_{i} s_{i}}-\frac{\phi \mu m_{j}}{m_{j} s_{j}+\phi m_{i} s_{i}} \cdot \frac{m_{i} s_{i}}{m_{j} s_{j}+\phi m_{i} s_{i}}\right] .
\end{aligned}
$$

Hence, the impact of trade opening on a country- $i$ firm can be decomposed in three effects: (i) the first term represents the market crowding effect in the home country, (ii) the second is the market expansion effect in the 
foreign country, and (iii) the third is the market crowding effect in the foreign country. In these terms, $\phi \mu m_{j}$ is the effective size of the foreign market for a country- $i$ firm, while $m_{i} s_{i}+\phi m_{j} s_{j}$ is the effective number of firms competing in country $i$.

Clearly, when $\phi=0$, the third term vanishes and we obtain

$$
\frac{\partial \bar{w}_{i}}{\partial \phi}(\bar{s}, \bar{s} ; 0)=\frac{1}{\sigma}\left[-\frac{\mu m_{i}}{m_{i} \bar{s}} \cdot \frac{m_{j} \bar{s}}{m_{i} \bar{s}}+\frac{\mu m_{j}}{m_{j} \bar{s}}\right]=\frac{1}{\sigma} \frac{\mu}{\bar{s}}\left(-\frac{m_{j}}{m_{i}}+1\right) .
$$

Hence, for a country-1 firm, the market crowding effect in the home market is dominated by the market expansion effect since $m_{1}>m_{2}$, whereas the opposite holds for the small country. This is because the growth in the effective number of firms is bigger in the small country than in the small one.

When $\phi=1$, we have

$$
\begin{aligned}
\frac{\partial \bar{w}_{i}}{\partial \phi}(\bar{s}, \bar{s} ; 1)= & \frac{1}{\sigma}\left[-\frac{\mu m_{i}}{m_{i} \bar{s}+m_{j} \bar{s}} \cdot \frac{m_{j} \bar{s}}{m_{i} \bar{s}+m_{j} \bar{s}}\right. \\
& \left.+\frac{\mu m_{j}}{m_{j} \bar{s}+m_{i} \bar{s}}-\frac{\mu m_{j}}{m_{j} \bar{s}+m_{i} \bar{s}} \cdot \frac{m_{i} \bar{s}}{m_{j} \bar{s}+m_{i} \bar{s}}\right] \\
= & \frac{1}{\sigma} \cdot \frac{-\mu m_{i}+\mu m_{j}}{\left(m_{i}+m_{j}\right) \bar{s}} \cdot \frac{m_{j}}{m_{i}+m_{j}} .
\end{aligned}
$$

In this case, the home and foreign market crowding effects are strongest because countries are fully integrated. Their combination dominates the market expansion effect for a country-1 firm, whereas the opposite holds for a country-2 firm. Indeed, the impact of competition being perfectly symmetric, what the large country gains is more than offset by what it loses.

Assume now that $\phi \in(0,1)$. First, recall that $\mu m_{i}$ is the total expenditure of country-i's residents on the industrial good, which is constant regardless of the trade openness $\phi$. Assuming that $m_{1}>m_{2}$, a marginal increase in the access to the foreign market is always larger for the small country firms than for the large country firms. Second, since $m_{1} s_{1}>m_{2} s_{2}$, the effective number of competing firms in the large country, $m_{1} s_{1}+\phi m_{2} s_{2}$, 
is bigger than that in the small country, $\phi m_{1} s_{1}+m_{2} s_{2}$, but the difference between those numbers becomes smaller as $\phi$ rises. Consequently, as integration proceeds, the market crowding effect becomes stronger relative to the market expansion effect for the large country firms, and vice versa for the small country firms. What Proposition 3.5 says is that, during the first phase of integration, the market expansion effect dominates the market crowding effect for the large country as it does when $\phi=0$, so that the number of firms in the large country increases while that of the small one decreases. Conversely, during the second phase, the market crowding effect dominates the market expansion effect for the large country as it does when $\phi=1$, so that the large country workers face weaker incentives to get skilled, which in turn implies that some of the small country workers choose to become entrepreneurs.

Three final remarks are in order. First, it is worth stressing that all the properties derived above hold for any distribution of types. Our main assumption is the quasi-linearity of preferences, which allows us to abstract from the income effect and to isolate the market expansion and crowding effects which go only through the price index. Yet, the inverted U-shaped process remains valid with a Cobb-Douglas utility function. Hence, this result is not a consequence of the absence of an income effect. Second, as shown in Appendix A.1, the preceding analysis holds true even when firms are heterogeneous in terms of marginal costs instead of entry costs provided that individuals know their types before making the entry decision. Third, when both countries have the same size, all results boil down to a trivial outcome in which the two countries keep the same industrial structure during the integration process. 


\subsection{Global industrialization}

It remains to study the trajectory of the equilibrium as a function of the degree of openness. As $\phi$ changes, the entrepreneurial income changes, thus inducing some individuals to modify their occupational choice. Clearly, the mass of the individuals who switch occupation depends on the shape of the density unction $g$. If this function has a complex form, then so may be the equilibrium trajectory. The following assumption imposes a standard regularity condition on the density $g$ that allows us to obtain a simple and neat characterization of the equilibrium trajectory.

Assumption 3.1. The density function $g$ is $\rho$-concave for some $\rho>-1 / 2$.

Such an assumption is far from being new in the economics literature. ${ }^{9}$ It has been introduced by Caplin and Nalebuff (1991a, 1991b) and used extensively in differentiated oligopoly models (see, e.g., Anderson et al. 1992). Note that $\rho$-concavity with $\rho<0$ is a weaker requirement than log-concavity (0-concavity is equivalent to log-concavity). Hence, our assumption covers the class of log-concave densities, which include many probability distributions such as the Pareto, beta, Dirichlet, exponential, gamma, Laplace, normal, and Gumbel distributions. ${ }^{10}$ Thus, we find it fair to say that our $\rho$-concavity assumption imposes a relatively mild restriction on the density function $g$.

Under this regularity condition, we can show the following.

Lemma 3.6. Under Assumption 3.1, the locus of $\bar{E}\left(s_{1}, s_{2}\right)=0$ is strictly concave.

Proof. Because $g$ is $-1 / 2$-concave, the Prékopa-Borell theorem implies that $G$ is $\rho^{\prime}$-concave for some $\rho^{\prime}>-1$. This in turn implies that $1 / G$ is

\footnotetext{
${ }^{9}$ Recall that a function $f$ is $\rho$-concave if $f^{\rho}$ is concave.

${ }^{10}$ As shown by Prékopa (1971), log-concavity may require restrictions on the parameter values for some of these distributions.
} 
strictly convex (Caplin and Nalebuff, 1991b). Given (2.6), it then suffices to show that $d\left(G^{-1}(x) x\right) / d x=\left(G^{-1}\right)^{\prime}(x) x+G^{-1}(x)$ is increasing in $x$ for the statement to hold. Since $\left(G^{-1}\right)^{\prime}(x)=1 / G^{\prime}\left(G^{-1}(x)\right)$ and since $G^{-1}$ is increasing, this is amount to saying that

$$
\frac{G(\alpha)}{G^{\prime}(\alpha)}+\alpha
$$

is increasing in $\alpha$. Taking the derivative of this expression, it is readily verified that this holds if and only if

$$
2\left(G^{\prime}(\alpha)\right)^{2}-G(\alpha) G^{\prime \prime}(\alpha)>0
$$

for all $\alpha$, which means that $1 / G$ is strictly convex. $\|$

The slope of the locus of $E\left(s_{1}, s_{2}\right)=0$ is $-m_{1} / m_{2}$ at $(\bar{s}, \bar{s})$. Provided $m_{1}>m_{2}$, Lemma 3.6 and Observation 2.1 imply that

$$
\left|\frac{d n_{1}^{*}(\phi)}{d \phi}\right|<\left|\frac{d n_{2}^{*}(\phi)}{d \phi}\right|
$$

for all $\phi \neq 0,1, \hat{\phi}$. Therefore, the size of the manufacturing sector in the small country is more sensitive to variations in trade obstacles than in the large one.

Denote by $N^{*}(\phi)$ the total number of firms in the whole economy:

$$
N^{*}(\phi)=m_{1} s_{1}^{*}(\phi)+m_{2} s_{2}^{*}(\phi) .
$$

Since $n_{2}^{*}$ decreases (respectively, increases) faster than $n_{1}^{*}$ (respectively, decreases) over the interval $(0, \hat{\phi})$ (resp., $(\hat{\phi}, 1))$, we have:

Proposition 3.7. Suppose that $m_{1} \neq m_{2}$. Under Assumption 3.1, $N^{*}(\phi)$ decreases over $(0, \hat{\phi})$ but increases over $(\hat{\phi}, 1)$.

In other words, as trade barriers are gradually removed, the global economy experiences the destruction of firms and the shrinking of variety, but faces the creation of firms and the widening of variety when international 
integration gets sufficiently deep. By making the whole array of varieties available in the global economy accessible to all consumers, the first integration phase induces less individuals to become entrepreneurs. On the other hand, during the second phase, the global market is sufficiently integrated to make the incentives to get entrepreneurs stronger and to bring the level of industrialization back to its initial level.

At this stage, it is worth stressing the analogy between the foregoing proposition and the bell-shaped curve of spatial development obtained in economic geography (Ottaviano and Thisse, 2004). In the former, there is no labor mobility between countries, but occupational choice makes endogenous the industrial structure of each country. In the latter, there is no sectoral mobility of labor, but the migration of workers between countries permits the emergence of economic agglomerations. The analogy lies in the fact that, during the first phase of integration, the two countries become more dissimilar, while their industrial structure converges during the second one.

\section{The impact of externality and heterogeneity}

As discussed in the introduction, the birth of firms often flourishes in countries in which agglomeration and network externalities increase the productivity of newly created firms. In such a context, firms enjoy external increasing returns. Note that this effect depends only upon the number of firms, not on their individual characteristics as in the section above. Furthermore, these externalities are confined to each country in order to capture the welldocumented fact that the scope of agglomeration externalities and spillovers is limited in space (Audretsch and Feldman, 2004; Rosenthal and Strange, 2004). To achieve our goal, we use a general reduced-form expression $h_{i}$ to study the impact of these externalities on the market outcome so that there is no need to describe the various processes that stand behind them. Specifically, we assume that producing $q$ units of a variety in country $i$ now 
requires $1 / h_{i}\left(n_{i}\right) \leq 1$ units of entrepreneurship and $q$ units of labor. In other words, increasing the number of local firms amounts to reducing the fixed requirement of entrepreneurial units. Or, put differently, externalities allow an entrepreneur to run a number $h_{i}\left(n_{i}\right) \geq 1$ of firms producing each a single variety. We assume that $h_{i}$ is continuously differentiable and increasing in $n_{i} \in\left[0, m_{i}\right]$. In equilibrium, the total mass of varieties produced in country $i$ is therefore equal to

$$
N_{i}=n_{i} h_{i}\left(n_{i}\right)
$$

so that $N=n_{1} h_{1}\left(n_{1}\right)+n_{2} h_{2}\left(n_{2}\right)$. In an entrepreneurship equilibrium, an individual of type $\alpha$ becomes an entrepreneur if and only if she makes an income $y_{i}=h_{i}\left(n_{i}\right) w_{i}$ higher than $\alpha$, where $w_{i}$ is the income earned from running a single firm. The equilibrium income $y_{i}$ of an entrepreneur living in country $i$ is now given by (see $(2.3)$ ):

$$
y_{i}\left(n_{i}, n_{j}\right)=\frac{1}{\sigma}\left[\frac{\mu m_{i} h_{i}\left(n_{i}\right)}{n_{i} h_{i}\left(n_{i}\right)+\phi n_{j} h_{j}\left(n_{j}\right)}+\phi \frac{\mu m_{j} h_{i}\left(n_{i}\right)}{n_{j} h_{j}\left(n_{j}\right)+\phi n_{i} h_{i}\left(n_{i}\right)}\right] .
$$

Accordingly, an entrepreneurship equilibrium is defined to be a pair $\left(n_{1}^{*}, n_{2}^{*}\right)$ such that

$$
n_{1}^{*}=F_{1}\left[y_{1}\left(n_{1}^{*}, n_{2}^{*}\right)\right] \quad n_{2}^{*}=F_{2}\left[y_{2}\left(n_{1}^{*}, n_{2}^{*}\right)\right] .
$$

It is readily verified that (2.4) holds true when $w_{i}$ is replaced by $y_{i}$, and thus all entrepreneurship equilibria lie on the locus of $E\left(n_{1}, n_{2}\right)=0$ as defined in (2.6). As long as the externality is sufficiently weak for a unique entrepreneurship equilibrium to exist, this one behaves as does the equilibrium described in Section 3. However, when the externality becomes strong enough, there are multiple equilibria, which may behave very differently (Cooper and John, 1988; Matsuyama, 1991).

Our purpose being to study the stabilizing effect of individual heterogeneity, in order to keep the analysis simple we assume that the two countries are identical. In other words, countries now have the same size, i.e., $m_{1}=m_{2}$, which is normalized to 1 so that $n_{i}=s_{i}$, the same density of 
types, i.e., $F_{1}=F_{2}=F$ (with a density $f$ and a common support $[\underline{\alpha}, \bar{\alpha}]$ ), and the same externality function, i.e., $h_{1}=h_{2}=h$ with $h(\cdot)>0$ and $h^{\prime}(\cdot) \geq 0$. In such a context, there is always a symmetric entrepreneurship equilibrium. Yet, in the presence of externalities, equilibria involving very different industrial structures typically exist as well. We first show that the same holds in our setting once externalities are sufficiently strong.

We then revisit these issues by emphasizing the stabilizing effect of the heterogeneity of individuals. To this end, we distinguish between local and global heterogeneity. More precisely, we demonstrate that sufficient local heterogeneity makes the symmetric entrepreneurship equilibrium locally stable, while a sufficient amount of global heterogeneity leads to the uniqueness, hence the global stability, of this equilibrium. Having shown that, even with asymmetric countries, we find it reasonable to expect that sufficient global heterogeneity generates a unique entrepreneurship equilibrium, the behavior of which is similar to the one described in Section 3.

\subsection{Externality and multiplicity}

As a preliminary step, we identify a sufficient condition under which our setting displays multiple equilibria. Recall that all equilibria are given by the intersection points of the following two loci:

$$
\begin{aligned}
& D_{1}\left(n_{1}, n_{2}\right)=F\left[y_{1}\left(n_{1}, n_{2}\right)\right]-n_{1}=0 \\
& D_{2}\left(n_{1}, n_{2}\right)=F\left[y_{2}\left(n_{1}, n_{2}\right)\right]-n_{2}=0 .
\end{aligned}
$$

Let $\bar{n} \in[0,1]$ be the unique solution to

$$
F\left(\frac{\mu}{\sigma n}\right)=n
$$

Observe that the symmetric state $(\bar{n}, \bar{n})$ is always an equilibrium irrespective of $h(\cdot)$ and $\phi$. Let

$$
\bar{y}=y_{i}(\bar{n}, \bar{n})=\frac{\mu}{\sigma \bar{n}} .
$$


In order to check whether there exist other equilibria, we study the shape of the two loci $D_{1}\left(n_{1}, n_{2}\right)=0$ and $D_{2}\left(n_{1}, n_{2}\right)=0$ in the $n_{1}-n_{2}$ plane. First, the locus $D_{i}\left(n_{1}, n_{2}\right)=0$ intersects the $n_{j}$-axis with $j \neq i$ at $n_{j}>1$ because $\underline{\alpha}<y_{i}^{\min }$. Likewise, $D_{i}\left(n_{1}, n_{2}\right)=0$ intersects the $n_{i}$-axis at $n_{i}<1$ because $y_{i}^{\max }<\bar{\alpha}$. Thus, due to continuity, the two loci intersect at other points if

$$
-\frac{\partial D_{1}}{\partial n_{1}}(\bar{n}, \bar{n}) / \frac{\partial D_{1}}{\partial n_{2}}(\bar{n}, \bar{n})>-1
$$

or

$$
f(\bar{y})\left[\frac{\partial y_{1}}{\partial n_{1}}(\bar{n}, \bar{n})-\frac{\partial y_{1}}{\partial n_{2}}(\bar{n}, \bar{n})\right]-1>0
$$

since $\partial y_{1} / \partial n_{2}<0$. Note that, by symmetry, this condition implies that the same holds for $i=2$.

Let $\eta_{h}$ be the elasticity of the externality function $h$ evaluated at $n=\bar{n}$ :

$$
\eta_{h}=\frac{\bar{n} h^{\prime}(\bar{n})}{h(\bar{n})} .
$$

Note that an increasing value of $\eta_{h}$ means that the agglomeration externality, evaluated at the symmetric equilibrium, becomes more reactive to a small deviation in the mass of entrepreneurs.

Let $\eta_{F}$ be the elasticity of the distribution function $F$ evaluated at $\alpha=\bar{y}$ :

$$
\eta_{F}=\frac{\bar{y} f(\bar{y})}{F(\bar{y})} .
$$

Since $f(\bar{y}) \bar{y}=\eta_{F} F(\bar{y})$ and $F(\bar{y})=\bar{n}$ by definition of $\bar{n}$, it must be that $f(\bar{y}) \bar{y} / \bar{n}=\eta_{F}$. Hence, the sufficient condition (4.5) implies the following result.

Proposition 4.1. Assume that the two countries are identical. Then, there always exists a symmetric entrepreneurship equilibrium, whereas asymmetric equilibria also exist if

$$
\eta_{h}>\frac{(1-\phi)^{2}+(1+\phi)^{2} / \eta_{F}}{4 \phi}
$$


Since the right hand side of (4.6) decreases from $\infty$ to $1 / \eta_{F}$ as $\phi$ increases from 0 to 1 , for low degrees of trade openness the externality at the symmetric equilibrium must be strong for the condition (4.6) to holds. Consequently, once agglomeration economies are at work, trade liberalization is likely to foster the emergence of asymmetric industrial structures between trading partners that are otherwise identical.

It is readily verified that

$$
\begin{aligned}
\frac{\partial y_{1}}{\partial n_{1}}(\bar{n}, \bar{n}) & =\bar{y} \frac{2 \phi \bar{n} h^{\prime}(\bar{n})-\left(1+\phi^{2}\right) h(\bar{n})}{(1+\phi)^{2} \bar{n} h(\bar{n})} \\
& =\frac{2 \phi}{(1+\phi)^{2}} \frac{\bar{y}}{\bar{n}}\left(\eta_{h}-\frac{1+\phi^{2}}{2 \phi}\right)
\end{aligned}
$$

and

$$
\begin{aligned}
\frac{\partial y_{1}}{\partial n_{2}}(\bar{n}, \bar{n}) & =-\bar{y} \frac{2 \phi\left[\bar{n} h^{\prime}(\bar{n})+h(\bar{n})\right]}{(1+\phi)^{2} \bar{n} h(\bar{n})} \\
& =-\frac{2 \phi}{(1+\phi)^{2}} \frac{\bar{y}}{\bar{n}}\left(\eta_{h}+1\right) .
\end{aligned}
$$

As expected, an increase in the number of entrepreneurs $n_{1}$ gives rise to two opposite effects in country 1 . The former stems from the agglomeration externality that, everything else equal, fosters an increase in the entrepreneurs' income by lowering the fixed cost they bear to launch a new variety. The latter is due to the more intense competition unleashed by the larger number of locally produced varieties; as usual, it tends to lower $y_{1}$. When there is autarky, the agglomeration externality has no impact since $y_{1}\left(n_{1}, n_{2}\right)=\mu / \sigma n_{1}$ is independent of $h(\cdot)$. However, once the two economies are open to trade, this externality may affect the industrial structure of both countries. Note first that, when there are no externalities $\left(h^{\prime}(n) \equiv 0\right)$, the only force at work is the market crowding effect so that

$$
\frac{\partial y_{1}}{\partial n_{1}}(\bar{n}, \bar{n})<0
$$

As seen in Section 3, the symmetric equilibrium is thus unique. The market crowding effect still dominates when the intensity of the agglomeration 
externality is weak. On the other hand, once the agglomeration externality effect is sufficiently large, there also exist asymmetric entrepreneurship equilibria, involving a larger number of entrepreneurs in one country than in the other. Specifically, (4.7) shows that the net effect of increasing $n_{1}$ is positive for country 1 entrepreneurs when the agglomeration externality at the symmetric equilibrium is sufficiently strong for

$$
\eta_{h}>\left(1+\phi^{2}\right) / 2 \phi
$$

to hold. This condition may be given a nice interpretation. For that, observe that $\partial y_{1} / \partial n_{1}$ can be decomposed as follows. Let $y_{1}^{\mathrm{H}}$ be the first term in (4.1) and $y_{1}^{\mathrm{F}}$ the second term. Then, we have

$$
\frac{\partial y_{1}^{\mathrm{H}}}{\partial n_{1}}(\bar{n}, \bar{n})=\frac{\phi}{(1+\phi)^{2}} \frac{\bar{y}}{\bar{n}}\left(\eta_{h}-\frac{1}{\phi}\right)
$$

and

$$
\frac{\partial y_{1}^{\mathrm{F}}}{\partial n_{1}}(\bar{n}, \bar{n})=\frac{\phi}{(1+\phi)^{2}} \frac{\bar{y}}{\bar{n}}\left(\eta_{h}-\phi\right) .
$$

Both effects are positive when $\eta_{h}$ exceeds $1 / \phi$ and $\phi$. Condition (4.8) thus holds if and only if $\eta_{h}$ is larger than the arithmetic mean of $1 / \phi$ and $\phi$. In the limit when there is no trade cost, the condition boils down to $\eta_{h}>1$. Note, finally, that an increase in $n_{2}$ has only a market crowding effect in country 1 since the externality is localized. This implies that $\partial y_{1} / \partial n_{2}$ is always negative.

In what follows, we show that the heterogeneity of individuals has a stabilizing effect in that heterogeneity tends to work in the opposite direction from externality. To this end, we use the concepts of local and of global heterogeneity. 


\subsection{Local heterogeneity and stability}

To study the local stability of equilibria, we consider the myopic best response dynamics given by

$$
\begin{aligned}
& \dot{n}_{1}(t)=F\left[y_{1}\left(n_{1}(t), n_{2}(t)\right)\right]-n_{1}(t) \\
& \dot{n}_{2}(t)=F\left[y_{2}\left(n_{1}(t), n_{2}(t)\right)\right]-n_{2}(t) .
\end{aligned}
$$

Observe that the set of entrepreneurship equilibria is identical to the set of rest points of this dynamics. We identify a local condition on the distribution of types for the symmetric equilibrium $(\bar{n}, \bar{n})$ to be stable with respect to the dynamics (4.9).

We know from the foregoing that the symmetric equilibrium $(\bar{n}, \bar{n})$ is stable if

$$
-\frac{\partial D_{1}}{\partial n_{1}}(\bar{n}, \bar{n}) / \frac{\partial D_{1}}{\partial n_{2}}(\bar{n}, \bar{n})<-1
$$

or, equivalently, if

$$
\eta_{h}<\frac{(1-\phi)^{2}+(1+\phi)^{2} / \eta_{F}}{4 \phi}
$$

We borrow the concept of spread from Rothschild and Stiglitz (1970) and restrict our attention to spread around the symmetric equilibrium $\bar{y}$.

Definition 4.1. A distribution $\tilde{F}$ is a spread of $F$ around $\bar{y}$ if $\tilde{F}(\bar{y})=F(\bar{y})$, and $\tilde{F}(\alpha)>F(\alpha)$ for all $\alpha<\bar{y}$ and $\tilde{F}(\alpha)<F(\alpha)$ for all $\alpha>\bar{y}$.

When $\tilde{F}$ (with the density $\tilde{f}$ ) is a spread of $F$, it must be that

$$
\tilde{f}(\bar{y})<f(\bar{y})
$$

By continuity of the two densities, this inequality must hold in some neighborhood $(\bar{y}-\varepsilon, \bar{y}+\varepsilon)$ of $\bar{y}$. In other words, spreading $F$ around $\bar{y}$ implies that its density gets smaller in $(\bar{y}-\varepsilon, \bar{y}+\varepsilon)$. This in turn means that individuals whose types are in the vicinity of $\bar{y}$ are more dispersed under $\tilde{F}$ than under $F$. Hence, by spreading the distribution of types around $\bar{y}$, we can make the 
population more heterogeneous around $\bar{y}$. This is why we may refer to it as local heterogeneity.

We are now equipped to show that a sufficient amount of heterogeneity around $\bar{y}$ leads to the stability of $(\bar{n}, \bar{n})$. Indeed, when $\tilde{f}(\bar{y})$ tends to zero, $\eta_{\tilde{F}}$ also tends to zero, so that the right hand side of (4.10) goes to infinity. This implies that $(\bar{n}, \bar{n})$ is stable as long as $\tilde{f}(\bar{y})$ is sufficiently small. Thus, we have:

Proposition 4.2. If the distribution of types around $\bar{y}$ is sufficiently heterogeneous, then the symmetric equilibrium $(\bar{n}, \bar{n})$ is locally stable.

Intuitively, this proposition may be understood as follows. When the system (4.2) is perturbed around $(\bar{n}, \bar{n})$, individuals who are affected by the resulting change in income are those whose types are close to $\bar{y}$, whereas individuals whose types are away from $\bar{y}$ remain unaffected. At $(\bar{n}+\varepsilon, \bar{n}-\varepsilon)$ where $\varepsilon>0$, some country-1 individuals have a higher income and some country-2 individuals have a lower income than what they earn at $(\bar{n}, \bar{n})$. The fraction of country- 1 individuals affected by this income rise is given by

$$
\tilde{f}(\bar{y})\left(\frac{\partial y_{1}}{\partial n_{1}} \varepsilon-\frac{\partial y_{1}}{\partial n_{2}} \varepsilon\right)+o(\varepsilon) .
$$

If many individuals are concentrated around $\bar{y}$, then $\tilde{f}(\bar{y})$ is much greater than $\varepsilon$. Thus, because of the externality function, the income of country1 potential entrepreneurs is further increased in an interval that includes $(\bar{n}+\varepsilon, \bar{n}-\varepsilon)$. This in turn sparks a further increase in $n_{1}$, which moves further away from $\bar{n}$. On the contrary, if individuals are widely dispersed around $\bar{y}$, then $\tilde{f}(\bar{y})$ is much lower than $\varepsilon$. In this case, the individuals affected by the income rise are too few for the externality to amplify the perturbation. As a result, $n_{1}$ goes back towards $\bar{n}$, which is stable. A similar argument applies to $n_{2}$. 


\subsection{Global heterogeneity and uniqueness}

To capture the idea of global heterogeneity, we borrow the parameterization proposed by Herrendorf et al. (2000). Given $F$, let $\bar{n} \in(0,1)$ and $\bar{y} \in(\underline{\alpha}, \bar{\alpha})$ be as in (4.3) and (4.4), respectively. Then, define $F(\cdot \mid \gamma, \bar{y})$ as

$$
F(\alpha \mid \gamma, \bar{y})=F(\gamma \alpha+(1-\gamma) \bar{y})
$$

where $\gamma \in(0, \infty)$. Note that

$$
f(\alpha \mid \gamma, \bar{y})=\gamma f(\gamma \alpha+(1-\gamma) \bar{y})
$$

is the density of $F(\alpha \mid \gamma, \bar{y})$ on the support

$$
\left[\underline{\alpha}-\frac{1-\gamma}{\gamma}(\bar{y}-\underline{\alpha}), \bar{\alpha}+\frac{1-\gamma}{\gamma}(\bar{\alpha}-\bar{y})\right] .
$$

Thus, a lower value of $\gamma$ implies a more heterogeneous population of individuals. Indeed, as $\gamma$ decreases, the whole density of types gets more spread over a broader domain. By taking such a transformation of $F$, the population of individuals exhibits a wider array of types while, for all types, less individuals share the same one. Observe, however, that $F(\bar{y} \mid \gamma, \bar{y})=F(\bar{y})$ so that the value of $F(\alpha \mid \gamma, \bar{y})$ at $\bar{y}$ is the same as the value of the initial distribution there. Consequently, $(\bar{n}, \bar{n})$ remains the unique symmetric equilibrium of the economy when types are distributed according to the $\gamma$-transformation of $F$.

Note also that $\eta_{F(\cdot \mid \gamma, \bar{y})}=\gamma \eta_{F(\cdot)}$, whereas the system (4.2) must be replaced by

$$
D_{i}\left(n_{1}, n_{2} \mid \gamma, \bar{y}\right)=F\left(y_{i}\left(n_{1}, n_{2}\right) \mid \gamma, \bar{y}\right)-n_{i}
$$

so that $(\bar{n}, \bar{n})$ is the intersection point of the two loci $D_{1}\left(n_{1}, n_{2} \mid \gamma, \bar{y}\right)=0$ and $D_{2}\left(n_{1}, n_{2} \mid \gamma, \bar{y}\right)=0$.

We have the following.

Proposition 4.3. There exists $\bar{\gamma}>0$ such that the symmetric equilibrium $(\bar{n}, \bar{n})$ is unique and globally stable when $\gamma<\bar{\gamma}$. 
Proof. See Appendix A.2.

Thus, despite the presence of an agglomeration externality, when individuals display enough contrasted attitudes toward entrepreneurship, the symmetric outcome is the only equilibrium.

We provide a numerical example to illustrate Propositions 4.2 and 4.3. Consider a uniform distribution of types over (4.11) with $y_{0}=y_{1}(0,1)=$ $y_{2}(1,0), \underline{\alpha}=y_{0}$, and $\bar{\alpha}=2 \bar{y}-y_{0}$, where $\bar{y}$ is given by (4.4). The externality function is such that

$$
h\left(n_{i}\right)=1+A n_{i}^{\beta}
$$

The parameter values are as follows: $m_{1}=m_{2}=1, \beta=3.3, A=100, \sigma=3$, $\phi=0.17$, and $\mu=10$. Under these parameters, the symmetric equilibrium is given by $(\bar{n}, \bar{n})=(0.5,0.5)$.

Figures 2(a) to 2(c) describe the changes in the correspondence of equilibria associated with $\gamma$ decreasing from 1 to 0.5 . The equilibrium condition for country 1 is represented by the solid line, while the dashed line describes this condition for country 2. In Figure 2(a) where $\gamma=1$ and $[\underline{\alpha}, \bar{\alpha}]=[-1.95,15.28]$, it is readily verified that the symmetric equilibrium is unstable. In Figure 2(b) where $\gamma=0.75$ and $[\underline{\alpha}, \bar{\alpha}]=[-1.95,15.28]$, the symmetric equilibrium becomes stable although there exist two asymmetric stable equilibria. In Figure 2(c), which is drawn for $\gamma=0.5$ and $[\underline{\alpha}, \bar{\alpha}]=[-6.26,19.60]$, the symmetric equilibrium is unique and globally stable. Note that the lower bound of the support becomes negative when $\gamma$ is close to zero, thus violating our assumption that types are non-negative. We have chosen to keep the example as is because it is extremely simple and illustrative.

In many contemporary models of trade, industrial organization and development, externalities are used to show that strongly asymmetric equilibria may arise. In this perspective, Propositions 4.2 and 4.3 are potentially important because there is ample evidence that heterogeneity across indi- 


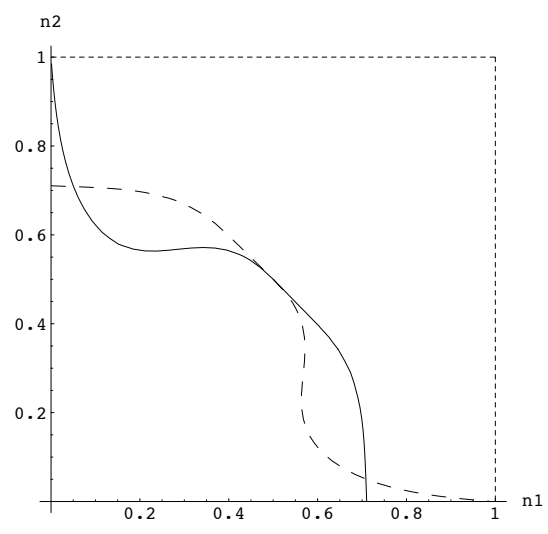

(a) $\gamma=1$

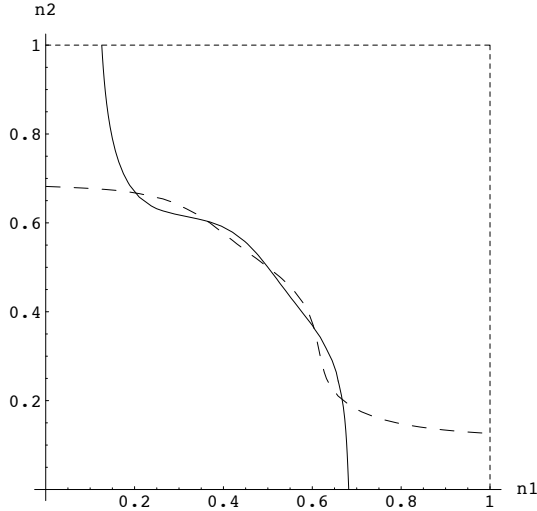

(b) $\gamma=0.75$

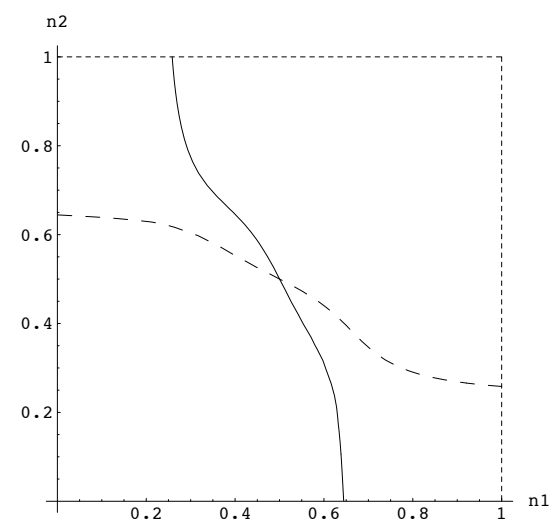

(c) $\gamma=0.5$

Figure 2: Heterogeneity and entrepreneurship

viduals is pervasive, whether externality effects are present or not. We may, therefore, expect heterogeneity across individuals to play an important role in the determination of the industry structure and the effects of trade liberalization. In the light of results discussed below, a result similar to Proposition 4.3 should hold even when countries are asymmetric. The behavior of the resulting unique equilibrium would then be similar to the one described in Section 3.

If individuals are identical, they all react in the same way, thus generating 
bang-bang aggregate behavior. The most famous example is undoubtedly given by the standard Bertrand model in which all consumers patronize the cheapest firm. In this case, it is easy to figure out why, when an agglomeration externality is at work, a minor deviation from the symmetric equilibrium gives rise to an unravelling process. By contrast, when individuals are locally heterogeneous, their aggregate behavior around the symmetric equilibrium is smoothed out. Furthermore, as individuals become globally more heterogeneous, i.e., as $\gamma$ decreases, the mass of individuals who choose to become an entrepreneur, regardless of the decisions made by the others, increases, and so does the mass of those who choose to be workers. In such a context, the sluggish behavior of individuals is less and less driven by the externality effect and, eventually, leads to the uniqueness, hence the global stability, of the symmetric equilibrium. Herrendorf et al. (2000) have made the same point in a model of occupational choice with infinitely lived agents and a closed economy, while we study the impact of trade within a general equilibrium model. ${ }^{11}$

This is reminiscent of existing results such as de Palma et al. (1985) and Anderson et al. (1994) who prove that a sufficient amount of heterogeneity guarantees the existence of an equilibrium in location and voting games. When individuals are heterogeneous, their sluggish aggregate behavior makes firms understand that they no longer gain a large share of customers by moving close to their ideal points. Furthermore, more heterogeneity makes the symmetric equilibrium unique because this leads firms to choose a location which yields the best average match between firms and dispersed consumers. Tabuchi and Thisse (2002) also show how global heterogeneity across potential migrants damper the agglomeration process in the core-periphery model, where the concentration of workers is driven by

\footnotetext{
${ }^{11}$ See also Dokumaci and Sandholm (2007), who make the same point in a version of Schelling's residential segregation model.
} 
a pecuniary externality. Like us, they prove that a sufficient amount of heterogeneity across individuals sustains the symmetric pattern as the only stable equilibrium. In the same spirit, McKelvey and Palfrey (1995) have shown that any finite game has a unique equilibrium when there is enough heterogeneity. ${ }^{12}$

\section{Conclusion}

The general press and anti-globalization groups often maintain that international economic integration leads to a more uniform and grey world. In view of our results, they seem to be right since market integration leads to the destruction of firms and varieties when the national economies become involved in the first stages of trade liberalization. In particular, developing countries (here the country with the small market and industrial basis) experience de-industrialization, an argument that lies behind the importsubstituting industrialization policies put forward in the 1960s (Hirschman, 1968). However, our results also suggest that a deeper economic integration leads to more diversity through the creation of new firms. In particular, the integration of developing countries to the world market might well be beneficial to them, as illustrated by the East Asian Miracle. Small countries then benefit from market integration by regaining market share in the manufacturing sector. What makes the whole process politically non-trivial is the fact that trading partners are unevenly affected as trade barriers gradually disappear. In the first phase, the share of developed countries (here the country with the large market and industrial basis) in manufacturing grows at the expense of that of developing countries, whereas the opposite holds

\footnotetext{
${ }^{12}$ It should be emphasized that all these results are obtained under the assumption that randomness is independent across agents. Indeed, as shown in the global game literature, when agents are highly correlated, we need a small amount of heterogeneity to obtain uniqueness (Morris and Shin, 2003, 2005; Ui, 2006).
} 
in the second phase.

Since our model bears some resemblance with economic geography, it is worth pursuing the comparison sketched in the foregoing. Through the creation of new firms, a country may develop a (much) bigger manufacturing sector than its trading partners. When agglomeration externalities are strong enough, one country might even accommodate a very large share of this sector. This is reminiscent of the core-periphery model proposed by Krugman (1991) with identical firms, in which agglomeration stems from the spatial mobility of firms and workers. However, contrary to us, low trade costs do not spark international convergence in Krugman's model. The bell-shaped curve of spatial development mentioned above is obtained once crowding forces that make the large agglomeration less attractive are added to the model. Therefore, unlike what Mundell (1957) thought, commodity trade and factor mobility are not necessarily good substitutes once markets are imperfect.

It should be emphasized, however, that the possible emergence of tradedriven international disparities needs qualification. Indeed, when potential entrepreneurs show very different opportunity costs, heterogeneity across individuals tends to reduce such disparities. The comparison made with other models also suggests that agents' heterogeneity could well be a general force that would destroy equilibria characterized by extreme features, thus pushing toward more balanced market outcomes. In a way, this is not a totally new idea. Ever since Hotelling (1929), we know that heterogeneity is often sufficient to get rid of knife-edge results obtained when economic agents are homogeneous. Clearly, more work is called for.

Finally, it is worth mentioning that our analysis confirms a well-established result, namely income inequalities within countries vary with the degree of trade openness. However, we have seen that they also vary with the size of the trading partners, a fact that has been overlooked in the literature. 
Growing inequalities may induce national governments to implement redistributional policies. The decision of a country to do so should trigger international reactions because it affects the welfare level in the others through the access of their residents to the array of varieties. Some preliminary analysis suggests that, for some levels of trade costs, a simultaneous move toward less inequality could be harmful to both countries. We leave this important topic for future research.

\section{Appendix}

\section{A.1 Marginal cost heterogeneity}

We assume that individuals are homogeneous in labor endowment. If an individual becomes a worker, then her equilibrium wage is still one. Each individual in country $i$ is identified by her type $\beta_{i}$, which is drawn according to the distribution function $F_{i}$ with support $\left[\underline{\beta}_{i}, \bar{\beta}_{i}\right]$, where $0<\underline{\beta}_{i}<\bar{\beta}_{i}$. Unlike Melitz (2003) and others, we assume ex ante heterogeneity: the individual knows her type $\beta_{i}$ before making her occupational choice.

If a type- $\beta_{i}$ individual becomes an entrepreneur, producing $q$ units of a variety requires $\beta_{i}^{1 /(\sigma-1)} q$ units of labor while the entry cost is given by her opportunity cost equal to the labor wage 1 (our expression for marginal costs will allow for a simpler exposition). Hence, firms are heterogeneous and a smaller value of $\beta_{i}$ corresponds to a more efficient firm. The profit of a country- $i$ firm of $\beta_{i}$-type is given by

$$
\pi_{i}\left[\beta_{i}\right]=\left(p_{i i}-\beta_{i}^{\frac{1}{\sigma-1}}\right) q_{i i} m_{i}+\left(p_{i j}-\beta_{i}^{\frac{1}{\sigma-1}}\right) \tau q_{i j} m_{j}-w_{i}\left[\beta_{i}\right]
$$

thus implying that its equilibrium mill prices are given by

$$
p_{i i}^{*}\left[\beta_{i}\right]=p_{i j}^{*}\left[\beta_{i}\right]=\frac{\sigma}{\sigma-1} \beta_{i}^{\frac{1}{\sigma-1}} .
$$

For a given number $n_{i} \in\left[0, m_{i}\right]$ of entrepreneurs in country $i$, the cutoff point is such that $\beta_{i}=F_{i}^{-1}\left(n_{i}\right)$. The corresponding country-i's aggregate 
efficiency is given by

$$
A_{i}\left(n_{i}\right):=\int_{\underline{\beta}_{i}}^{F_{i}^{-1}\left(n_{i}\right)} \beta^{-1} d F_{i}(\beta)
$$

which is increasing in $n_{i}$ (see expression (7) in Melitz (2003)).

Given $\left(n_{1}, n_{2}\right)$, the equilibrium price index in country $i$ can be shown to be equal to

$$
P_{i}=\frac{\sigma}{\sigma-1}\left(A_{i}\left(n_{i}\right)+\phi A_{j}\left(n_{j}\right)\right)^{-\frac{1}{\sigma-1}}
$$

where the (effective) number of firms in (2.2) is replaced by the (effective) aggregate efficiency of each country because marginal costs are no longer identical across firms.

It is then readily verified that the salary $w_{i}\left[\beta_{i}\right]\left(n_{1}, n_{2}\right)$ of a country- $i$ entrepreneur of type $\beta_{i}$ is now given by (compare with (2.3))

$$
w_{i}\left[\beta_{i}\right]\left(n_{1}, n_{2}\right)=B_{i}\left(n_{1}, n_{2}\right) \beta_{i}^{-1}
$$

where

$$
B_{i}\left(n_{1}, n_{2}\right):=\frac{1}{\sigma}\left[\frac{\mu m_{i}}{A_{i}\left(n_{i}\right)+\phi A_{j}\left(n_{j}\right)}+\phi \frac{\mu m_{j}}{A_{j}\left(n_{j}\right)+\phi A_{i}\left(n_{i}\right)}\right] .
$$

is independent of the entrepreneur's type (see expression (4) of Baldwin and Okubo (2006)). Function $B_{i}$ is to be interpreted as the average productivity in value. Formally, due to our definition of types, it plays the same role as function $w_{i}$ in Subsection 2.2. Because $w_{i}$ is multiplicatively separable in $B_{i}$ and $\beta_{i}$, the ratio of any two country- $i$ entrepreneurs' salaries only depends on their productivity levels.

As in (2.4), the salary of an entrepreneur is given by the constant fraction $1 / \sigma$ of her firm's revenue, which implies

$$
\sum_{i=1,2} \int_{\underline{\beta}_{i}}^{F_{i}^{-1}\left(n_{i}\right)} w_{i}\left[\beta_{i}\right]\left(n_{1}, n_{2}\right) d F_{i}\left(\beta_{i}\right)=\frac{\mu}{\sigma}\left(m_{1}+m_{2}\right) .
$$




\section{A.1.1 The entrepreneurship equilibrium}

A type- $\beta_{i}$ individual chooses to become an entrepreneur if and only if

$$
w_{i}\left[\beta_{i}\right]\left(n_{1}, n_{2}\right) \geq 1
$$

or, equivalently,

$$
\beta_{i} \leq B_{i}\left(n_{1}, n_{2}\right)
$$

An entrepreneurship equilibrium is a pair $\left(n_{1}^{*}, n_{2}^{*}\right)$ such that

$$
n_{1}^{*}=F_{1}\left[B_{1}\left(n_{1}^{*}, n_{2}^{*}\right)\right] \quad n_{2}^{*}=F_{2}\left[B_{2}\left(n_{1}^{*}, n_{2}^{*}\right)\right] .
$$

As in Subsection 2.3, such an equilibrium always exists. Again we have $\partial F_{i}\left[B_{i}\left(n_{i}, n_{j}\right)\right] / \partial n_{j}<0$, meaning that entrepreneurship decisions remain strategic substitutes between countries.

As in (2.6), the equilibrium always lie on the locus of $E\left(n_{1}, n_{2}\right)=0$ which now becomes

$$
E\left(n_{1}, n_{2}\right)=F_{1}^{-1}\left(n_{1}\right) A_{1}\left(n_{1}\right)+F_{2}^{-1}\left(n_{2}\right) A_{2}\left(n_{2}\right)-\frac{\mu}{\sigma}\left(m_{1}+m_{2}\right)
$$

since

$$
\int_{\underline{\beta}_{i}}^{F_{i}^{-1}\left(n_{i}\right)} w_{i}\left[\beta_{i}\right]\left(n_{1}, n_{2}\right) d F_{i}\left(\beta_{i}\right)=B_{i}\left(n_{1}, n_{2}\right) A_{i}\left(n_{i}\right) .
$$

The locus $E\left(n_{1}, n_{2}\right)=0$ is downward sloping. Observe that $\partial E / \partial n_{i}>0$.

\section{A.1.2 The impact of trade opening}

Assume $F_{i}=m_{i} G$, and denote $s_{i}=n_{i} / m_{i}$. As in Section 3, the salary function becomes

$$
\bar{w}_{i}\left[\beta_{i}\right]\left(s_{1}, s_{2} ; \phi\right)=\bar{B}_{i}\left(s_{1}, s_{2} ; \phi\right) \beta_{i}^{-1}
$$

where

$$
\bar{B}_{i}\left(s_{1}, s_{2} ; \phi\right):=\frac{1}{\sigma}\left[\frac{\mu m_{i}}{m_{i} a\left(s_{i}\right)+\phi m_{j} a\left(s_{j}\right)}+\phi \frac{\mu m_{j}}{m_{j} a\left(s_{j}\right)+\phi m_{i} a\left(s_{i}\right)}\right],
$$


and

$$
a\left(s_{i}\right):=\int_{\underline{\beta}}^{G^{-1}\left(s_{i}\right)} \beta^{-1} d G(\beta) .
$$

is independent of $i$.

As in Subsection 3.1, we define

$$
\bar{D}_{i}\left(s_{1}, s_{2} ; \phi\right):=G\left[\bar{B}_{i}\left(s_{1}, s_{2} ; \phi\right)\right]-s_{i}
$$

so that $\left(s_{1}^{*}(\phi), s_{2}^{*}(\phi)\right)$ is an entrepreneurship equilibrium for $\phi$ if and only if $\bar{D}_{i}\left(s_{1}^{*}(\phi), s_{2}^{*}(\phi) ; \phi\right)=0$ for $i=1,2$.

Finally, let $\bar{s}$ be defined by

$$
G\left(\frac{\mu}{\sigma a(\bar{s})}\right)=\bar{s}
$$

Replacing throughout $\bar{w}_{i}$ by $\bar{B}_{i}$, the argument that goes from Observation 3.1 to Observation 3.4 in Subsection 3.1 can be repeated. As a consequence, the counterpart of Proposition 3.5 holds in the case of marginal cost heterogeneity. The economic intuition of this result is the same as that presented in Subsection 3.1.

\section{A.2 Proof of Proposition 4.3}

Lemma A.1. Assume that the density $f$ is bounded. If $\gamma \rightarrow 0$, then $f(\cdot \mid \gamma, \bar{y})$ converges uniformly to zero on $\mathbb{R}$.

Proof. Let $M>0$ be such that $f(\alpha) \leq M$ for all $\alpha \in \mathbb{R}$, where $f$ is defined to be zero outside the support $[\underline{\alpha}, \bar{\alpha}]$. Then, we have

$$
\sup _{\alpha \in \mathbb{R}} f(\alpha \mid \gamma, \bar{y})=\sup _{\alpha \in \mathbb{R}} \gamma f(\gamma \alpha+(1-\gamma) \bar{y}) \leq \gamma M \rightarrow 0
$$

as $\gamma \rightarrow 0 . \quad \|$

Proof of Proposition 4.3. Because of symmetry, it is sufficient for uniqueness to show that there exists $\bar{\gamma}>0$ such that for all $\gamma \in(0, \bar{\gamma})$, the slope of the $D_{1}$-locus at $\left(n_{1}, n_{2}\right)$ is smaller than -1 when $\left(n_{1}, n_{2}\right)$ is an equilibrium 
Note that (2.3) implies that under the assumption $h(0)>0$, the equilibrium income $y_{i}$ has a positive lower bound $y^{\min }>0$ and an upper bound $y^{\max }$, which are independent of the distribution (and hence, of $\gamma$ ). When the interval $(\underline{\alpha}, \bar{\alpha})$ is wide enough to include $\left[y^{\min }, y^{\max }\right]$, we have $F\left(y^{\min }\right)>$ 0 . Any equilibrium thus belongs to the compact set $\left[F\left(y^{\min }\right), F\left(y^{\max }\right)\right] \times$ $\left[F\left(y^{\min }\right), F\left(y^{\max }\right)\right]$. Since $y^{\min }<\bar{y}<y^{\max }$, for any $\gamma<1$ we have $F\left(y^{\min }\right)<$ $F\left(y^{\min } \mid \gamma, \bar{y}\right)$ and $F\left(y^{\max } \mid \gamma, \bar{y}\right)<F\left(y^{\max }\right)$.

Observe that $\partial y_{1} / \partial n_{1}$ and $\partial y_{1} / \partial n_{2}$ are continuous on $\left[F\left(y^{\min }\right), F\left(y^{\max }\right)\right] \times\left[F\left(y^{\min }\right), F\left(y^{\max }\right)\right]$, and thus there are constants $K_{1}>0$ and $K_{2}>0$ such that $\left|\left(\partial y_{1} / \partial n_{1}\right)\left(n_{1}, n_{2}\right)\right| \leq K_{1}$ and $\left|\left(\partial y_{1} / \partial n_{2}\right)\left(n_{1}, n_{2}\right)\right| \leq$ $K_{2}$ for all $\left(n_{1}, n_{2}\right) \in\left[F\left(y^{\min }\right), F\left(y^{\max }\right)\right] \times\left[F\left(y^{\min }\right), F\left(y^{\max }\right)\right]$. It follows from Lemma A.1 that, for all $\varepsilon>0$, there exists $\bar{\gamma}(\varepsilon)>0$ such that $\left|f\left(y_{1}\left(n_{1}, n_{2}\right) \mid \gamma, \bar{y}\right)\right|<\varepsilon / \max \left\{K_{1}, K_{2}\right\}$ for all $\gamma<\bar{\gamma}(\varepsilon)$ and any equilibrium $\left(n_{1}, n_{2}\right)$. Since $\left(\partial y_{1} / \partial n_{1}\right)\left(n_{1}, n_{2}\right)>0$ and $\left(\partial y_{1} / \partial n_{2}\right)\left(n_{1}, n_{2}\right)<0$, this implies that, for all $\varepsilon>0$, if $\gamma<\bar{\gamma}(\varepsilon)$, then

$$
\begin{aligned}
-1<\frac{\partial D_{1}}{\partial n_{1}}\left(n_{1}, n_{2} \mid \gamma, \bar{y}\right) & =f\left(y_{1}\left(n_{1}, n_{2}\right) \mid \gamma, \bar{y}\right) \frac{\partial y_{1}}{\partial n_{1}}\left(n_{1}, n_{2}\right)-1 \\
& \leq K_{1} f\left(y_{1}\left(n_{1}, n_{2}\right) \mid \gamma, \bar{y}\right)-1<-1+\varepsilon
\end{aligned}
$$

and

$$
\begin{aligned}
0>\frac{\partial D_{1}}{\partial n_{2}}\left(n_{1}, n_{2} \mid \gamma, \bar{y}\right) & =f\left(y_{1}\left(n_{1}, n_{2}\right) \mid \gamma, \bar{y}\right) \frac{\partial y_{1}}{\partial n_{2}}\left(n_{1}, n_{2}\right) \\
& \geq-K_{2} f\left(y_{1}\left(n_{1}, n_{2}\right) \mid \gamma, \bar{y}\right)>-\varepsilon
\end{aligned}
$$

for all equilibria $\left(n_{1}, n_{2}\right)$. Thus, setting $\bar{\gamma}=\bar{\gamma}(1 / 2)$, we have that if $\gamma<\bar{\gamma}$, then

$$
\frac{\partial D_{1}}{\partial n_{1}}\left(n_{1}, n_{2} \mid \gamma, \bar{y}\right) / \frac{\partial D_{1}}{\partial n_{2}}\left(n_{1}, n_{2} \mid \gamma, \bar{y}\right)<-1
$$

for all equilibria $\left(n_{1}, n_{2}\right)$. This implies that the equilibrium is unique.

Since the two-dimensional competitive dynamical system (4.9) is known to be formally equivalent to a cooperative dynamical system, this equilibrium is globally stable (Hofbauer and Sigmund, 1998, Section 3.4). ॥ 


\section{References}

[1] Amiti, M. and C.A. Pissarides 2005. Trade and industrial location with heterogeneous labor. Journal of International Economics 67, 392-412.

[2] Anderson, S.P., A. de Palma and J.-F. Thisse. 1992. Discrete Choice Theory of Product Differentiation. Cambridge, MA, The MIT Press.

[3] Anderson, S.P., A. Kats and J.-F. Thisse. 1994. Probabilistic voting and platform selection in multi-party elections. Social Choice and Welfare $11,305-322$.

[4] Audretsch, D.B. and M.P. Feldman. 2004. Knowledge spillovers and the geography of innovation. In J.V. Henderson and J.-F. Thisse (eds.) Handbook of Regional and Urban Economics vol. 4. Amsterdam, North Holland, 2713-2739.

[5] Baldwin, R. and T. Okubo. 2006. Heterogeneous firms, agglomeration and economic geography: spatial selection and sorting. Journal of Economic Geography 6, 323-346.

[6] Caplin, A. and B. Nalebuff. 1991a. Aggregation and social choice: A mean voter theorem. Econometrica 59, 1-24.

[7] Caplin, A. and B. Nalebuff. 1991b. Aggregation and imperfect competition: on the existence of equilibrium. Econometrica 59, 25-60.

[8] Casson, M. 2005. Entrepreneurship and the theory of the firm. Journal of Economic Behavior and Organization 58, 327-348.

[9] Cooper, R and A. John. 1988. Coordinating coordination failures in Keynesian models. Quarterly Journal of Economics 103, 441-463.

[10] de Palma, A., V. Ginsburgh, Y.Y. Papageorgiou and J.-F. Thisse. 1985. The principle of minimum differentiation holds under sufficient heterogeneity. Econometrica 53, 767-781. 
[11] Dinoupoulos, E., K. Fujiwara and K. Shimomura. 2007. International trade patterns under quasi-linear preferences. Mimeo, University of Florida.

[12] Dokumaci, E. and W.H. Sandholm. 2007. Schelling redux: an evolutionary dynamic model of residential segregation. Mimeo, University of Wisconsin at Madison.

[13] Duranton, G. and D. Puga. 2004. Micro-foundations of urban agglomeration economies. In J.V. Henderson and J.-F. Thisse (eds.) Handbook of Regional and Urban Economics vol. 4. Amsterdam, North Holland, 2063-2117.

[14] Eeckhout, J. and B. Jovanovic. 2008. Occupational choice and development. Mimeo, University of Pennsylvania.

[15] Fujita, M. and J.-F. Thisse. 2009. New Economic Geography: an appraisal on the occasion of Paul Krugman's 2008 Nobel Prize in Economics. Regional Science and Urban Economics 39, 109-119.

[16] Glaeser, E. and W. Kerr. 2008. Local industrial conditions and entrepreneurship: how much of the spatial distribution can we explain? NBER Working Paper 14407.

[17] Helpman, E, M. Melitz and S. Yeaple. 2004. Export versus FDI with heterogeneous firms. American Economic Review 94, 300-316.

[18] Herrendorf, B., A. Valentinyi, and R. Waldmann. 2000. Ruling out multiplicity and indeterminacy: the role of heterogeneity. Review of Economic Studies 67, 295-307.

[19] Hirschman, A.O. 1968. The political economy of import-substituting industrialization in Latin America. Quarterly Journal of Economics 82, $1-32$. 
[20] Hofbauer, J. and K. Sigmund 1998. Evolutionary Games and Population Dynamics. Cambridge, Cambridge University Press.

[21] Holmes, T. J. and J. A. Schmitz. 1990. A theory of entrepreneurship and its application to the study of business transfers. Journal of Political Economy 98, 265-294.

[22] Hotelling, H. 1929. Stability in competition, Economic Journal 39, 4157.

[23] Jovanovic, B. 1982. Selection and the evolution of industry. Econometrica 50, 649-670.

[24] Krugman, P.R. 1980. Scale economies, product differentiation, and the pattern of trade. American Economic Review 70, 950-959.

[25] Krugman, P. 1991. Increasing returns and economic geography. Journal of Political Economy 99, 483-499.

[26] Krugman, P. and A. Venables. 1995. Globalization and the inequality of nations. Quarterly Journal of Economics 110: 857-880.

[27] Lucas, R. 1978. On the size distribution of business firms. Bell Journal of Economics 9, 508-523.

[28] Martin, P. and C. A. Rogers 1995. Trade effects of regional aid. In R.E. Baldwin, P. Haapararanta, and J. Kiander (eds.) Expanding Membership of the European Union. Cambridge, Cambridge University Press.

[29] Matsuyama, K. 1991. Increasing returns, industrialization, and indeterminacy of equilibrium, Quarterly Journal of Economics 106, 617-650.

[30] McKelvey, R. and T.R. Palfrey 1995. Quantal response equilibria in normal form games. Games and Economic Behavior 10, 6-38. 
[31] Melitz, M. 2003. The impact of trade on intraindustry reallocations and aggregate industry productivity. Econometrica 71, 1695-1725.

[32] Melitz, M., and G.I.P. Ottaviano. 2008. Market size, trade, and productivity. Review of Economic Studies 75, 295-316.

[33] Minniti, M. 2005. Entrepreneurship and network externalities. Journal of Economic Behavior and Organization 57, 1-27.

[34] Morris, S. and H. S. Shin. 2003. Global games: theory and applications. In M. Dewatripont, L.P. Hansen, and S.J. Turnovsky (eds.) Advances in Economics and Econometrics: Theory and Applications: Eighth World Congress, Volume 1. Cambridge, Cambridge University Press.

[35] Morris, S. and H. S. Shin. 2005. Heterogeneity and uniqueness in interaction games. In L.E. Blume and S.N. Durlauf (eds.) The Economy as an Evolving Complex System III. Oxford, Oxford University Press, $207-242$.

[36] Mundell, R. 1957. International trade and factor mobility. American Economic Review 47, 321-335.

[37] Nocke, V. 2006. A gap for me: entrepreneurs and entry. Journal of the European Economic Association 4, 929-955.

[38] Ottaviano, G.I.P. and J.-F. Thisse. 2004. Agglomeration and economic geography. In J.V. Henderson and J.-F. Thisse (eds.) Handbook of Regional and Urban Economics vol. IV. Amsterdam, North Holland, 25632608 .

[39] Pflüger, M. 2004. A simple, analytically solvable, Chamberlinian agglomeration model. Regional Science and Urban Economics 34, 565573. 
[40] Prékopa, A. 1971. Logarithmic concave measures with application to stochastic programming. Acta Scientiarum Mathematicarum 32, 301316.

[41] Rosenthal, S. and W. Strange. 2004. Evidence on the nature and sources of agglomeration economies. In: J.V. Henderson and J.-F. Thisse, editors, Handbook of Regional ad Urban Economics. Volume IV. Amsterdam: North-Holland, 2120-2171.

[42] Rothschild, M. and J.E. Stiglitz. 1970. Increasing risks: I. A definition. Journal of Economic Theory 2, 225-243.

[43] Shane, S. and S. Venkataraman. 2000. The promise of entrepreneurship as a field of research. The Academy of Management Review 25, 217-226.

[44] Tabuchi, T. and J.-F. Thisse. 2002. Taste heterogeneity, labor mobility and economic geography. Journal of Development Economics 69, 155177.

[45] Ui, T. 2006. Correlated quantal responses and equilibrium selection. Games and Economic Behavior 57, 361-369.

[46] Wennekers, S., A. van Stel, M. Carree and R. Thurik. 2009. The relation between entrepreneurship and economic development: is it U-shaped? Foundations and Trends in Entrepreneurship 5, forthcoming.

[47] World Bank. 1991. World Development Report. The Challenge of Development. Oxford: Oxford University Press.

[48] World Trade Organization. 2001. Market access: unfinished business. Post-Uruguay Round inventory and issues. Special Studies 6. 


\section{Recent titles \\ CORE Discussion Papers}

2009/8. Michel M. DENUIT, Louis EECKHOUDT and Mario MENEGATTI. Adding independent risks in an insurance portfolio: which shape for the insurers' preferences?

2009/9. Antoine BOMMIER and Stéphane ZUBER. The Pareto principle of optimal inequality.

2009/10. Raouf BOUCEKKINE, Jacek B. KRAWCZYK and Thomas VALLEE. Environmental negotiations as dynamic games: Why so selfish?

2009/11. Théophile T. AZOMAHOU, Raouf BOUCEKKINE and Phu NGUYEN-VAN. Promoting clean technologies under imperfect competition.

2009/12. Patrice PIERETTI and Skerdilajda ZANAJ. On tax competition, public goods provision and jurisdictions' size.

2009/13. Jeroen V.K. ROMBOUTS and Lars STENTOFT. Bayesian option pricing using mixed normal heteroskedasticity models.

2009/14. Gauthier de MAERE d'AERTRYCKE and Yves SMEERS. The valuation of power futures based on optimal dispatch.

2009/15. Thierry BRECHET, Tsvetomir TSACHEV and Vladimir M. VELIOV. Prices versus quantities in a vintage capital model.

2009/16. François VANDERBECK and Laurence A. WOLSEY. Reformulation and decomposition of integer programs.

2009/17. Marc FLEURBAEY, Erik SCHOKKAERT and Koen DECANCQ. What good is happiness?

2009/18. David DE LA CROIX and Michel LUBRANO. The tradeoff between growth and redistribution: ELIE in an overlapping generations model.

2009/19. Thierry BRECHET and Fabien PRIEUR. Can education be good for both growth and the environment?

2009/20. Giacomo SBRANA and Andrea SILVESTRINI. What do we know about comparing aggregate and disaggregate forecasts?

2009/21. Marc GERMAIN, Henry TULKENS and Alphonse MAGNUS. Dynamic core-theoretic cooperation in a two-dimensional international environmental model.

2009/22. Claude D'ASPREMONT and Rodolphe DOS SANTOS FERREIRA. Household behavior and individual autonomy.

2009/23. Helmuth CREMER, Philippe DE DONDER and Pierre PESTIEAU. Education and social mobility.

2009/24. Maria Eugenia SANIN and Francesco VIOLANTE. Understanding volatility dynamics in the EU-ETS market: lessons from the future.

2009/25. Marco DI SUMMA and Laurence A. WOLSEY. Lot-sizing with stock upper bounds and fixed charges.

2009/26. Johanna M.M. GOERTZ and François MANIQUET. On the informational efficiency of simple scoring rules.

2009/27. Jean GABSZEWICZ, Ornella TAROLA and Skerdilajda ZANAJ. On uncertainty when it affects successive markets.

2009/28. Jerzy A. FILAR, Jacek B. KRAWCZYK and Manju AGRAWAL. On production and abatement time scales in sustainable development. Can we loosen the sustainability screw?

2009/29. María Eugenia SANIN and Skerdilajda ZANAJ. Clean technology adoption and its influence on tradeable emission permit prices.

2009/30. Antoine BOMMIER, Marie-Louise LEROUX and Jean-Marie LOZACHMEUR. On the public economics of annuities with differential mortality.

2009/31. Gilles GRANDJEAN, Ana MAULEON and Vincent VANNETELBOSCH. Connections among farsighted agents.

2009/32. Axel GAUTIER and Xavier WAUTHY. On the nature of price competition under universal service obligations: a note.

2009/33. Santanu S. DEY and Laurence A. WOLSEY. Constrained infinite group relaxations of MIPs.

2009/34. Jean-François MAYSTADT and Philip VERWIMP. Winners and losers among a refugeehosting population. 


\section{Recent titles}

\section{CORE Discussion Papers - continued}

2009/35. Pierre DEHEZ. Allocation of fixed costs and the weighted Shapley value.

2009/36. Sabien DOBBELAERE, Roland Iwan LUTTENS and Bettina PETERS. Starting an R\&D project under uncertainty.

2009/37. Carlotta BALESTRA and Davide DOTTORI. Aging society, health and the environment.

2009/38. Alain PHOLO BALA. Urban concentration and economic growth: checking for specific regional effects.

2009/39. Alain PHOLO BALA. Gates, hubs and urban primacy in Sub-Saharan Africa.

2009/40. Nicolas BOCCARD. On efficiency, concentration and welfare.

2009/41. Taoufik BOUEZMARNI, Jeroen V.K. ROMBOUTS and Abderrahim TAAMOUTI. A nonparametric copula based test for conditional independence with applications to Granger causality.

2009/42. Josez KONINGS and Hylke VANDENBUSSCHE. Antidumping protection hurts exporters: firm-level evidence from France.

2009/43. Pierre PESTIEAU and Uri M. POSSEN. Retirement as a hedge.

2009/44. Santanu S. DEY and Laurence A. WOLSEY. Lifting group inequalities and an application to mixing inequalities.

2009/45. Jean CAVAILHES, Pierre FRANKHAUSER, Dominique PEETERS and Isabelle THOMAS. Residential equilibrium in a multifractal metropolitan area.

2009/46. Daisuke OYAMA, Yasuhiro SATO, Takatoshi TABUCHI and Jacques-François THISSE. On the impact of trade on industrial structures: The role of entry cost heterogeneity.

\section{Books}

Public goods, environmental externalities and fiscal competition: 22 selected papers in public economics by Henry Tulkens, edited and introduced by Parkash Chander, Jacques Drèze, C. Knox Lovell and Jack Mintz, Springer, Boston 2006 (588 pp.).

V. GINSBURGH and D. THROSBY (eds.) (2006), Handbook of the economics of art and culture. Amsterdam, Elsevier.

J. GABSZEWICZ (ed.) (2006), La différenciation des produits. Paris, La découverte.

L. BAUWENS, W. POHLMEIER and D. VEREDAS (eds.) (2008), High frequency financial econometrics: recent developments. Heidelberg, Physica-Verlag.

P. VAN HENTENRYCKE and L. WOLSEY (eds.) (2007), Integration of AI and OR techniques in constraint programming for combinatorial optimization problems. Berlin, Springer.

P-P. COMBES, Th. MAYER and J-F. THISSE (eds.) (2008), Economic geography: the integration of regions and nations. Princeton, Princeton University Press.

J. HINDRIKS (ed.) (2008), Au-delà de Copernic: de la confusion au consensus ? Brussels, Academic and Scientific Publishers.

J-M. HURIOT and J-F. THISSE (eds) (2009), Economics of cities. Cambridge, Cambridge University Press.

\section{CORE Lecture Series}

C. GOURIÉROUX and A. MONFORT (1995), Simulation Based Econometric Methods.

A. RUBINSTEIN (1996), Lectures on Modeling Bounded Rationality.

J. RENEGAR (1999), A Mathematical View of Interior-Point Methods in Convex Optimization.

B.D. BERNHEIM and M.D. WHINSTON (1999), Anticompetitive Exclusion and Foreclosure Through Vertical Agreements.

D. BIENSTOCK (2001), Potential function methods for approximately solving linear programming problems: theory and practice.

R. AMIR (2002), Supermodularity and complementarity in economics.

R. WEISMANTEL (2006), Lectures on mixed nonlinear programming. 